\title{
Structure and properties of nanocrystalline materials
}

\author{
C SURYANARAYANA \\ Institute for Materials and Advanced Processes, University of Idaho, Moscow, ID \\ 83844-3026, USA
}

MS received 24 June 1994

\begin{abstract}
The present article reviews the current status of research and development on the structure and properties of nanocrystalline materials. Nanocrystalline materials are polycrystalline materials with grain sizes of up to about $100 \mathrm{~nm}$. Because of the extremely small dimensions, a large fraction of the atoms in these materials is located at the grain boundaries, and this confers special attributes. Nanocrystalline materials can be prepared by inert gas-condensation, mechanical alloying, plasma deposition, spray conversion processing, and many other methods. These have been briefly reviewed.

A clear picture of the structure of nanocrystalline materials is emerging only now. Whereas the earlier studies reasoned out that the structure of grain boundaries in nanocrystalline materials was quite different from that in coarse-grained materials, recent studies using spectroscopy, high-resolution electron microscopy, and computer simulation techniques showed unambiguously that the structure of the grain boundaries is the same in both nanocrystalline and coarse-grained materials. A critical analysis of this aspect and grain growth is presented.

The properties of nanocrystalline materials are very often superior to those of conventional polycrystalline coarse-grained materials. Nanocrystalline materials exhibit increased strength/hardness, enhanced diffusivity, improved ductility/toughness, reduced density, reduced elastic modulus, higher electrical resistivity, increased specific heat, higher thermal expansion coefficient, lower thermal conductivity, and superior soft magnetic properties in comparison to conventional coarse-grained materials. Recent results on these properties, with special emphasis on mechanical properties, have been discussed.

New concepts of nanocomposites and nanoglasses are also being investigated with special emphasis on ceramic composites to increase their strength and toughness. Even though no components made of nanocrystalline materials are in use in any application now, there appears to be a great potential for applications in the near future. The extensive investigations in recent years on structure-property correlations in nanocrystalline materials have begun to unravel the complexities of these materials, and paved the way for successful exploitation of the alloy design principles to synthesize better materials than hitherto available.
\end{abstract}

Keywords. Nanocrystalline materials; synthesis; gas condensation; mechanical alloying; spray conversion; structure of grain boundaries; properties; diffusion; mechanical properties; ductility improvement; electrical properties; specific heat; thermal expansion; optical properties; magnetic properties; corrosion behaviour; catalytic properties; applications.

\section{Introduction}

Metallurgists and materials scientists have been conducting research investigations for several centuries to develop materials which are 'stronger, stiffer, and lighter' than the existing materials and also capable of use at elevated ('hotter') temperatures. The high-tech industries in the developed countries have given an added fillip to these efforts. Several novel and non-equilibrium processing methods have been developed during the past few decades to improve the performance of the existing materials; these include rapid solidification from the liquid state (Anantharaman and Suryanarayana 1987; Liebermann 1993), mechanical alloying (Koch 1991), plasma processing 
(El-Kaddah 1992), vapour deposition (Bickerdike et al 1984-85), etc. A central underlying theme in all these methods is to energize the material to bring it into a highly non-equilibrium (metastable) state (also including a possible change of state from the solid to liquid or gas) through melting, evaporation, irradiation, application of pressure, storing of mechanical energy, etc. (Turnbull 1981). The material is then brought to another lower-energy metastable state by quenching or related processes when it can exist as a supersaturated solid solution, metastable crystalline or quasicrystalline phase, or even in a glassy state, affording ample opportunities to modify the crystal structures and/or microstructures. These processes have led to considerable improvement in the properties of a number of alloy systems and consequently some industrial applications; these have been described and fully documented in the references listed above.

A novel way of transforming a material to a metastable state is to reduce its grain size to very small values of a few nanometers $\left(1 \mathrm{~nm}=10^{-9} \mathrm{~m}\right)$ when the proportion of atoms in the grain boundaries is equivalent to or higher than those inside the grains. This type of metastability can be classified as morphological meta (or 'in') stability in the scheme of Turnbull (1981). Materials with such small grain sizes are now referred to as nanocrystalline materials (and also as nanocrystals, nanostructures, nanophase materials, or nanometer-sized crystalline solids), and have been shown to have properties vastly superior to those exhibited by conventional grain-sized ( $>10 \mu \mathrm{m}$ ) polycrystalline materials. It is the combination of unique compositions and novel microstructures that leads to the extraordinary potential of the nanocrystalline materials.

There has been a continued increase in the research investigations in recent years on the synthesis/processing, characterization, properties, and potential applications of these novel materials. A new journal entitled 'Nanostructured Materials', published by Pergamon Press, was started in 1992. In addition to several national conferences and also as a part of other symposia, a series of international conferences is planned exclusively to discuss the developments in nanostructured materials. The first international conference was held in Cancun, Mexico, in September 1992 and the second is scheduled to be held in Stuttgart, Germany, in October 1994.

The purpose of the present article is to present a very broad overview of the structure and properties of nanocrystalline materials. Potential applications of these novel materials will also be highlighted. This field has been reviewed earlier with emphasis on some selected topics (Andres et al 1989; Birringer 1989; Froes and Suryanarayana 1989; Gleiter 1989, 1992; Suryanarayana and Froes 1989, 1992a; Siegel 1990, 1991a, b, 1994; Dagani 1992; Gryaznov et al 1992; Shull 1993; Andrievski 1994). However, there is no comprehensive review related to the materials aspects; this review fulfills that gap.

\section{Classification}

Nanocrystalline materials are single-phase or multi-phase polycrystals, the crystal size of which is of the order of a few (typically 1 to 100) nanometers in at least one dimension. Thus, they can be basically equiaxed in nature and will be termed nanostructure crystallites (three-dimensional [3-D] nanostructures), or they can consist of a lamellar structure, and will be termed a layered nanostructure (one-dimensional 
[1-D] nanostructure), or they can be filamentary in nature (two-dimensional [2-D] nanostructure) (Suryanarayana and Froes 1992a). Additionally, Siegel (1994) considers zero-dimensional atom clusters and cluster assemblies. Table 1 shows this classification and figure 1 illustrates the four types of nanostructures schematically. The magnitudes of length and width are much greater than thickness in the layered nanocrystals, and length is substantially larger than width or diameter in filamentary nanocrystals. The nanocrystalline materials may contain crystalline, quasicrystalline, or amorphous phases and can be metals, ceramics, or composites.

Amongst the above, maximum attention has been paid to the synthesis, consolidation, and characterization of the 3D-nanostructured crystallites followed by the 1D-layered nanostructures. While the former are expected to find applications based on their high strength, improved formability, and a good combination of soft magnetic properties, the latter are visualized for electronic applications. Relatively few investigations have been carried out on the $2 \mathrm{D}$-filamentary nanostructures and it is only recently that zero-dimensional clusters are being investigated to tailor the optical properties.

Table 1. Classification of nanocrystalline materials.

\begin{tabular}{lll}
\hline Dimensionality & Designation & $\begin{array}{l}\text { Typical method(s) } \\
\text { of synthesis }\end{array}$ \\
\hline Three-dimensional & $\begin{array}{l}\text { crystallites } \\
\text { (equiaxed) } \\
\text { filamentary }\end{array}$ & $\begin{array}{l}\text { gas condensation } \\
\text { mechanical alloying } \\
\text { chemical vapour } \\
\text { deposition }\end{array}$ \\
One-dimensional & $\begin{array}{l}\text { layered } \\
\text { (lamellar) } \\
\text { clusters }\end{array}$ & $\begin{array}{l}\text { vapour deposition } \\
\text { electrodeposition }\end{array}$ \\
\hline
\end{tabular}

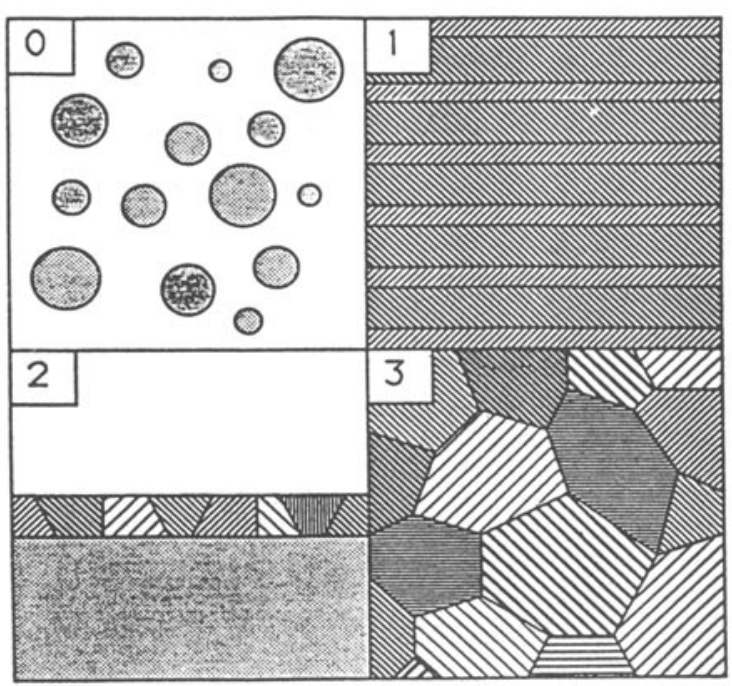

Figure 1. Schematic of the four types of nanocrystalline materials (Siegel 1994). 


\section{Characteristics}

A schematic representation of a hard-sphere model of an equiaxed nanocrystalline metal is shown in figure 2. Two types of atoms can be distinguished: crystal atoms with nearest neighbour configuration corresponding to the lattice and boundary atoms with a variety of interatomic spacings, differing from boundary to boundary. A nanocrystalline metal contains typically a high number of interfaces $\left(\sim 6 \times 10^{25} \mathrm{~m}^{-3}\right)$ with random orientation relationships, and consequently, a substantial fraction of atoms lies in the interfaces. Assuming that grains have the shape of spheres or cubes, the volume fraction of nanocrystalline materials associated with the boundaries can be calculated (Mütschele and Kirchheim 1987b) as

$$
C=3 \Delta / d
$$

where $\Delta$ is the average grain boundary thickness and $d$ the average grain diameter. Thus, the volume fraction of atoms in the grain boundaries can be as much as $50 \%$ for $5 \mathrm{~nm}$ grains and decrease to about $30 \%$ for $10 \mathrm{~nm}$ grains and $3 \%$ for $100 \mathrm{~nm}$ grains.

In recent years, it has become apparent that it is the total intercrystalline region (consisting of grain boundaries and triple junctions, i.e. intersection lines of three or more adjoining crystals) which is more important than grain boundaries alone since at very small grain sizes triple junctions become an important component of the microstructure. Since neither of the above grain shapes (spheres or cubes) is reasonable nor are they suitable for deriving triple junction volume fractions, Palumbo et al (1990b) considered the grains to have the regular fourteen-sided tetrakaidecahedron shapes, with the hexagonal faces representing the grain boundaries, and edges corresponding to triple junctions. Assuming the maximum diameter of an inscribed sphere as the grain size, $d$, and the intercrystalline component as an outer 'skin' of

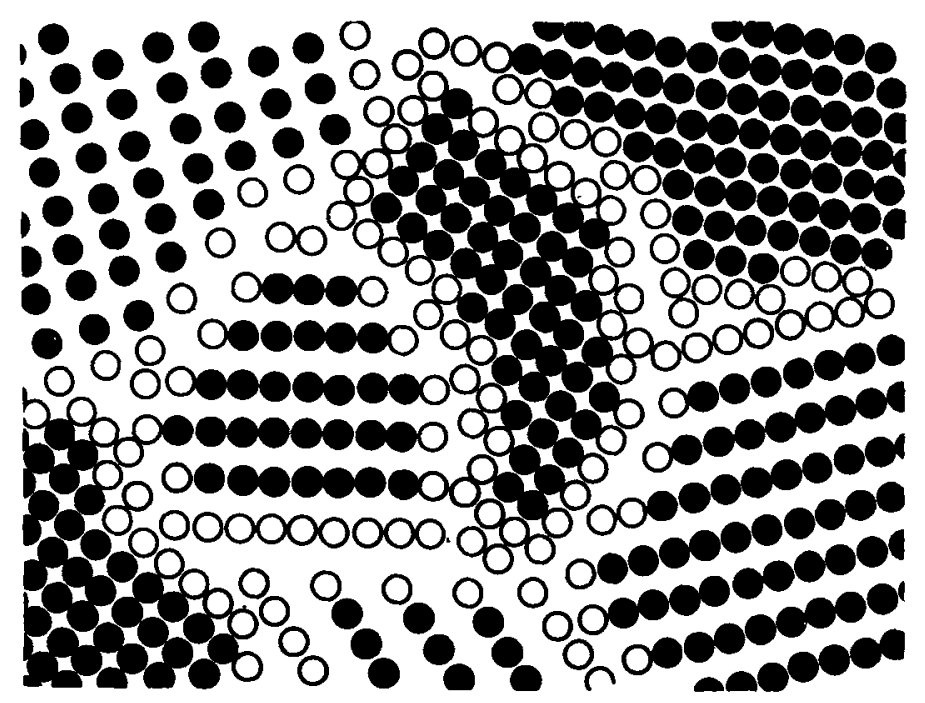

Figure 2. Schematic representation of an equiaxed nanocrystalline metal distinguishing. between the atoms associated with the individual grains (filled circles) and those constituting the grain boundary network (open circles) (Gleiter 1989). 
the tetrakaidecahedron with a thickness of $\Delta / 2$, the intercrystalline volume fraction has been calculated as

$$
V_{\mathrm{ic}}=1-[(d-\Delta) / d]^{3} .
$$

The grain boundary component has been assessed as

$$
V_{\mathrm{gb}}=\left[3 \Delta(d-\Delta)^{2}\right] / d^{3},
$$

and therefore, the volume fraction associated with triple junctions $V_{\mathrm{t} j}$ is then given by

$$
V_{\mathrm{tj}}=V_{\mathrm{ic}}-V_{\mathrm{gb}} \text {. }
$$

All of the above equations are valid for $d>\Delta$. Figure 3 shows the variation of $V_{\text {ic, }}$ $V_{\mathrm{gb}}$, and $V_{\mathrm{ij}}$ as a function of the grain size, $d$, and suggests that these values can be as much as $70-80 \%$ at very small sizes of $2-3 \mathrm{~nm}$ (Suryanarayana et al 1992).

From the foregoing, it is clear that nanocrystalline metals can be considered to consist of two structural components - the numerous, small crystallites with longrange order and different crystallographic orientations constituting the "crystalline component' and a network of intercrystalline regions, the structure of which differs from region to region, called the 'interfacial' component. This interfacial component has an average atomic density which is 10 to $30 \%$ less than the crystal density depending on the type of chemical bonding between the atoms. Further, the boundaries exhibit a broad spectrum of interatomic spacings and if these are averaged, there would be neither long-range nor short-range order. This has led Gleiter to coin the nanocrystals as 'a new form of matter' Both these characteristics of the interfacial component (reduced density and wide distribution of interatomic spacings) have been

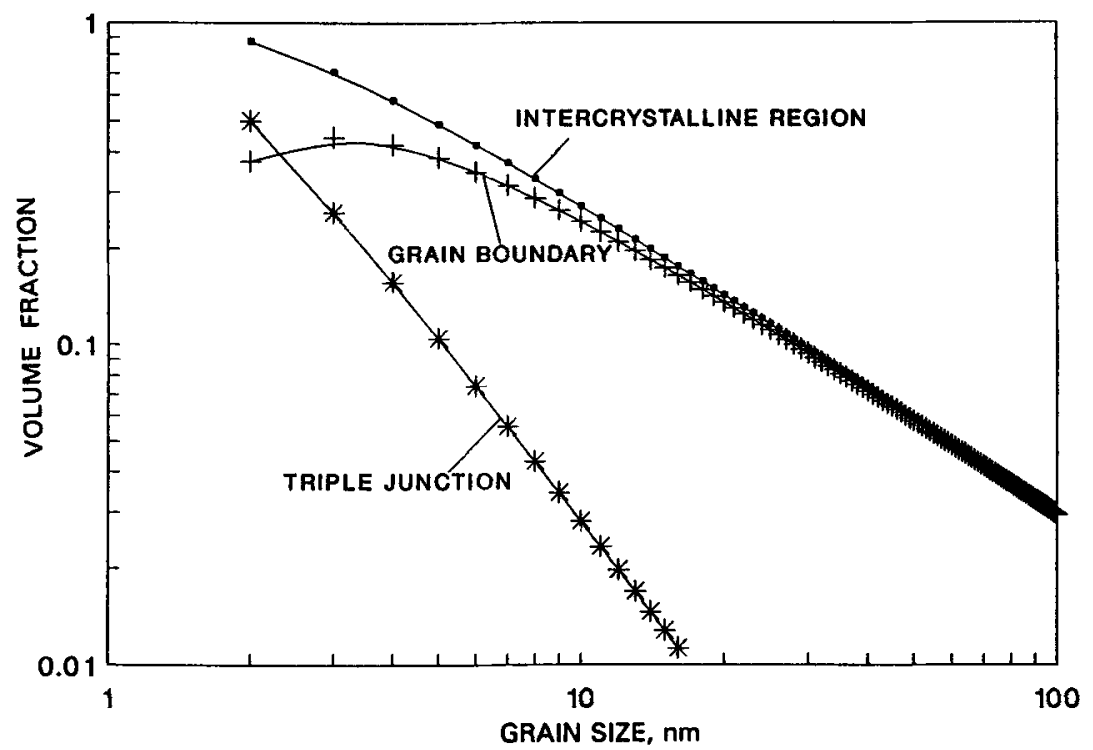

Figure 3. The effect of grain size on the calculated volume fractions for intercrystalline regions, grain boundaries, and triple junctions, assuming a grain boundary thickness of $1 \mathrm{~nm}$ (Suryanarayana et al 1992). 
confirmed by experimental observations using high-resolution electron microscopy, grazing incidence diffraction of X-rays, small-angle X-ray scattering, EXAFS (extended $X$-ray absorption fine structure) and other techniques (Gleiter 1989, 1992).

\section{Synthesis}

Increased activity on the synthesis of nanocrystalline materials in recent years dates back to the pioneering investigations of Herbert Gleiter of the University of Saarlandes in Germany in 1981 (Gleiter 1981). He synthesized ultrafine nanometer-sized metallic particles using an inert gas condensation technique and consolidated them in situ into small disks under ultra-high vacuum conditions. Since then a number of techniques have been developed in which the starting material can be either in the solid, liquid, or gaseous states (table 2).

In principle, any method capable of producing very fine grain-sized polycrystalline materials (by increasing the nucleation rate and reducing the growth rate during formation) can be utilized to produce nanocrystalline materials. The methods which have been commonly employed to synthesize these materials include inert gas condensation (Birringer et al 1984; Siegel 1991b), mechanical alloying (Koch 1993), spray conversion processing (Kear and McCandlish 1993), sputtering (Chang et al 1992), physical vapour deposition (Bickerdike et al 1984-85), electrodeposition (Lashmore and Dariel 1988), co-precipitation (Mayo 1993; Ritter et al 1993), sol-gel process (Roy and Roy 1984), sliding wear (Rigney 1988), spark erosion (Berkowitz and Walter 1987), plasma processing (Chou and Phillips 1992; Taylor et al 1993), laser ablation (Mandich et al 1987), hydrothermal pyrolysis (Kriechbaum and Kleinschmitt 1989), and thermophoretic forced flux system (Haas et al 1993). The grain size, morphology, and texture can be varied by suitably modifying/controlling the process variables in each of these methods.

Controlled crystallization of the amorphous phases produced by any of the above methods (e.g. mechanical alloying, vapour deposition, electrodeposition) or by rapid solidification from the liquid state can also be used to produce nanocrystalline materials. In fact, the most common method to produce nanocrystalline magnetic materials has been to obtain an amorphous phase by rapidly solidifying the melt of appropriate composition and then crystallizing the glassy phase at a relatively low

Table 2. Methods to synthesize nanocrystalline materials.

\begin{tabular}{ll}
\hline Starting phase & Techniques \\
\hline Vapour & Inert gas condensation \\
& Sputtering \\
& Plasma processing \\
& Vapour deposition \\
& (physical and chemical) \\
& Electrodeposition \\
Liquid & Rapid solidification \\
& O Mechanical alloying/milling \\
Solid & Sliding wear \\
& Spark erosion \\
\hline
\end{tabular}


temperature. These materials-referred to as FINEMET-were first investigated by Yoshizawa et al (1988) and this method has now become an established practice to study the structure and properties of nanocrystalline magnetic materials (Suryanarayana and Froes 1993; Lu et al 1991b). There have also been several basic investigations during the last 2-3 years to define the conditions under which ultrafine microstructures form starting from the glassy phases (Köster et al 1991, 1994).

Even though all of the above methods have been used with different levels of success to produce nanocrystalline phases in a variety of materials, gas condensation, mechanical alloying, chemical precipitation and spray conversion processing techniques have been most commonly employed to produce 3-D equiaxed nanocrystallites while vapour deposition, sputtering and electrodeposition techniques have been used to synthesize the 1-D layered nanocrystals; the sol-gel process has been commonly used to generate clusters.

Amongst all the techniques mentioned above, the gas condensation (or its modifications), mechanical alloying, and spray conversion processing techniques have been most commonly employed to produce large quantities of nanocrystalline materials. The gas condensation technique involves evaporation of the metal or a mixture of metals inside an ultra high-vacuum (UHV) chamber filled with helium gas. As a result of interatomic collisions with the helium atoms in the chamber, the evaporated metal atoms lose their kinetic energy and condense in the form of small crystals of loose powder which accumulate, due to convective flow, on a vertical liquid nitrogen-filled cold finger. The powder is stripped off the cold finger by moving an annular teflon ring down the length of the tube into a compaction device. The scraping and compaction processes also are carried out under UHV conditions to maintain cleanliness of the

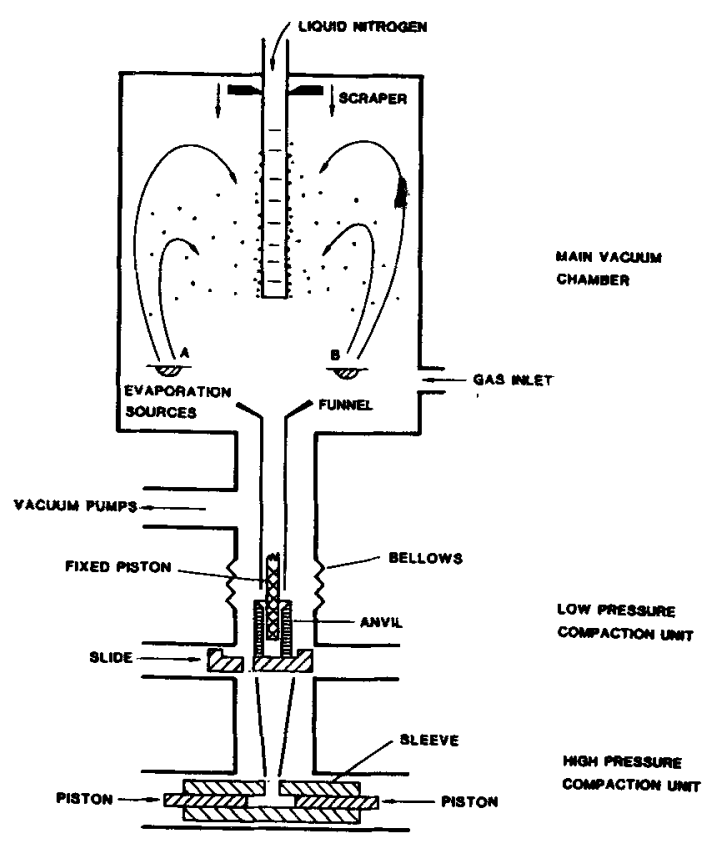

Figure 4. Schematic representation of a gas-condensation chamber for the synthesis of nanocrystalline materials (Siegel 1990). 
particle surfaces (and subsequent interfaces) and also to minimize the amount of any trapped gases (figure 4) (Siegel 1990). High densities of as-compacted samples have been measured with values of about 75 to $90 \%$ of bulk density for metal samples.

A full description of the technique, the variety of evaporation methods, and the effect of the process variables on the size, size distribution and constitution of the powder particles can be found, for example, in Gleiter (1989) and Siegel (1991b).

Mechanical alloying consists of repeated welding, fracturing, and rewelding of powder particles in a dry high-energy ball charge. In this process, mixtures of elemental or prealloyed powders are subjected to grinding under a protective atmosphere in equipment capable of high-energy compressive impact forces such as attrition mills, vibrating ball mills, and shaker mills. A majority of the work on nanocrystalline materials has been carried out in highly energetic small shaker mills. A very recent comprehensive review (Koch 1993) describes the process of mechanical alloying and the characteristics and properties of the nanocrystalline materials obtained. It has been shown that nanometer-sized grains can be obtained in almost any material after sufficient milling time. The grain sizes were found to decrease with milling time down to a minimum value which appeared to scale inversely with the melting temperature. Further, mechanical alloying of immiscible metals resulted in very large metastable solid solubilities; presumably related to solute segregation at the nanocrystalline grain boundaries.

The spray conversion processing of Kear and McCandlish (1993) to produce WC-Co nanocrystalline composite starts with the aqueous solution precursors such as ammonium metatungstate $\left[\left(\mathrm{NH}_{4}\right)_{6}\left(\mathrm{H}_{2} \mathrm{~W}_{12} \mathrm{O}_{40}\right) 4 \mathrm{H}_{2} \mathrm{O}\right]$ and $\mathrm{CoCl}_{2},\left[\mathrm{Co}\left(\mathrm{CH}_{3} \mathrm{COO}\right)_{2}\right]$, or cobalt nitrate $\left[\mathrm{Co}\left(\mathrm{NO}_{3}\right)_{2}\right]$. The solution mixture is aerosolized and rapidly spray dried to give extremely fine mixtures of tungsten and cobalt salts. This precursor powder is reduced with hydrogen and reacted with carbon monoxide in a fluidized-bed reactor to yield nanophase cobalt/tungsten carbide powder. The tungsten particles are $20-50 \mathrm{~nm}$ in size. To prevent the grain growth of tungsten, additions of inhibitors such as $\mathrm{VC}$ and $\mathrm{Cr}_{3} \mathrm{C}_{2}$ are made as binders during the sintering steps. Recently, vanadium is being introduced into the starting solution itself to achieve a more uniform distribution in the powder mixture. The process parameters are being further optimized and since the process is fully integrated, on-line control is also being planned.

Widespread application of nanocrystalline materials requires production of the powder in tonnage quantities and also efficient methods of consolidating the powders into bulk shapes. Since the gas condensation process is carried out completely under UHV conditions, the cost of production is high. However, the powder produced is very clean and the cleanliness between the particles can be maintained even after compaction. Mechanical alloying, on the other hand, is a proven commercial process to produce oxide-dispersion-strengthened nickel- and iron-base superalloy powders (Benjamin 1976) and can be easily adapted to produce nanocrystalline powders on a commercial scale. This should prove a relatively inexpensive method. But, contamination of the powder during milling (due to the fine size of the powder, atmosphere, and addition of process control agents to prevent excessive welding of powder particles amongst themselves and to the container walls) could prove a serious limitation of the process. Plasma processing can be another viable commercial process for making nanocrystalline powders.

Two companies in the USA have started producing nanocrystalline powders on a commercial scale. Nanophase Technologies at Darien (near Chicago), IL, markets 
metal and metal oxide powders produced by a modified inert gas condensation method. They plan to produce about 10-20 tons per year by summer of 1994. Even though they sell nanocrystalline $\mathrm{TiO}_{2}$ powder now at $\$ 50$ per pound, the company expects that the price will come down to about $\$ 10-20$ by the end of 1994 in view of the increased demand. Nanodyne, Inc. in New Brunswick, NJ, produces WC-Co composite powders by the spray conversion process. They produce about 100 tons of the ultrafine-grain composite a year and sell it for about $\$ 35$ per pound. Although conventional tungsten tool materials cost about $\$ 20$ a pound, the nanocrystalline materials could deliver up to four times the service life.

ULTRAM in Olten, Switzerland using the evaporation condensation method, and PSI Ltd. in Polegate, East Sussex, UK, using the physical vapour deposition technique, also produce large quantities of powders and sell them in the open market.

\section{Structure}

In order to understand the interrelationship between structure and properties, nanocrystalline materials need to be characterized on both atomic and nanometer scales. The microstructural features of importance include (1) grain size, distribution and morphology, (2) the nature and morphology of grain boundaries and interphase interfaces, (3) perfection and nature of intragrain defects, (4) composition profiles across grains and interfaces, and (5) identification of residual trapped species from processing. In the case of layered nanostructures, the features of importance are (1) thickness and coherency of interfaces, (2) composition profiles across interfaces, and (3) nature of defects.

There is a gamut of experimental techniques that can yield structural information on nanocrystalline materials. These include 'direct' microscopic techniques such as transmission electron microscopy (TEM), scanning tunneling microscopy (STM), field-ion microscopy (FIM), and the less direct electron, X-ray, and neutron diffraction techniques. Indirect spectroscopic tools, such as EXAFS, nuclear magnetic resonance, Raman and Mössbauer spectroscopies and positron annihilation spectroscopy, have also been used. Other useful tools employed include differential scanning calorimetry, mass spectroscopy, X-ray fluorescence, atomic absorption spectroscopy, Auger electron spectroscopy, and hydrogen absorption.

Owing to the ultrafine scale of these materials, traditional characterization tools such as TEM and X-ray and neutron diffraction are both necessary and useful to understand the structure of nanocrystalline materials. However, for microchemical analysis on the requisite fine scale, further advances in the state-of-the-art of instrumental capabilities will be necessary to obtain the desired lateral scale resolution. Only atom-probe FIM or STM seem to offer the required lateral scale resolution for such chemical mapping at present.

Gleiter and co-workers (Schaefer et al 1988; Birringer 1989; Gleiter 1989) and others (Ouyang et al 1993) have used a number of the above techniques to study the structure of nanocrystalline materials and interpreted most of their results in terms of a two-component microstructure-perfect long-range ordered atomic arrangement in the grains and a random interfacial component. The possibility was raised that the structure of the grain boundaries in nanocrystalline materials might have unique characteristics owing to the constraints imposed on the grain boundary atoms by 


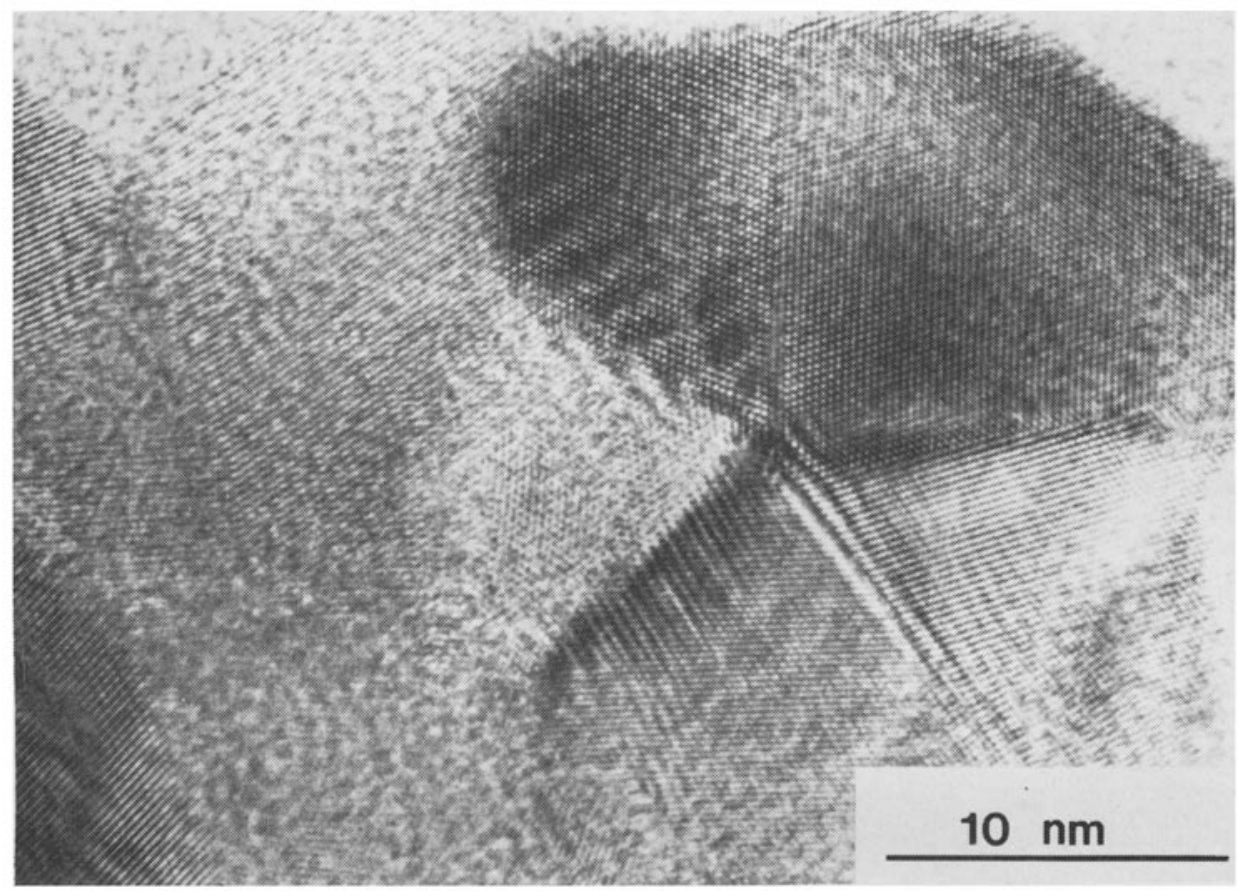

Figure 5. High-resolution electron micrograph of nanocrystalline copper sample produced by the gas-condensation technique (Nieman et al 1991a).

their synthesis via cluster consolidation. In recent years, however, there has been some confusion regarding the structure of the grain boundaries in nanocrystalline materials and also whether it is different from that in conventional coarse-grained polycrystalline materials. We shall briefly review the present situation on this aspect.

The microstructure of nanocrystalline metals has been investigated by highresolution TEM. These studies indicated that nanocrystalline metals consist of small crystallites of different crystallographic orientations separated by grain boundaries. Figure 5 shows a high-resolution transmission electron micrograph recorded from a nanocrystalline $\mathrm{Cu}$ specimen synthesized by the gas-condensation method (Nieman et al 1991a). From such micrographs (as well as from field-ion micrographs and by small-angle X-ray or neutron scattering data), grain sizes and their distributions have been determined. The grains exhibit typically narrow log-normal size distributions, i.e. they exhibit a single peak when the frequency is plotted on a linear scale against the log of the particle size.

The following features may be noted from the high-resolution electron micrographs of nanocrystalline materials:

(1) Most of the ultrafine grains are equiaxed and exhibit fringe contrast. The grains are randomly oriented with respect to one another and there is no apparent preferred orientation.

(2) The fringes abruptly stop in each grain at the grain boundary (Li D X et al 1993), indicating that there is little or no atomic disorder perpendicular to the imaged planes. 
(3) The grain boundary planes are basically flat but exhibit some local faceting (Thomas et al 1990), probably to bring the planes from both grains into registry.

(4) Neither voids nor dislocations have been observed in many investigations, even though positron annihilation spectroscopy (Schaefer et al 1988; Siegel et al 1988), and precise densitometry and porosimetry (Nieman et al 1990,1991b) measurements have clearly indicated the presence of porosity in nanocrystalline metals. Nieman et al (1991a), however, reported observation of abundant twinning and low-index, faceted crystal regions, while Wunderlich et al (1990) reported detection of isolated dislocations or dipoles. D X Li et al (1993) reported observation of grain boundary dislocations, five-fold twins, and edge and $60^{\circ}$ dislocations.

High-resolution TEM investigations have been carried out on nanocrystalline palladium (Thomas et al 1990; Wunderlich et al 1990; Li D X et al 1993), 440C martensitic steel (Ganapathi and Rigney 1990), and Fe-Mo-Si-B crystals (Li D X et al 1993). Wunderlich et al (1990) noted that the grain boundaries in nanocrystalline palladium appeared different from conventional coarse-grained palladium, and with a smaller grain boundary thickness of 0.4 to $0.6 \mathrm{~nm}$ as against the accepted value of $1 \mathrm{~nm}$. A qualitative difference in the contrast in a vicinity of $>0.6 \mathrm{~nm}$ at general grain boundaries (compared to conventional polycrystalline material) was observed. This was attributed to the high energy states of the grain boundaries in nanocrystalline materials, a situation not observed in conventional materials. They also noted that in the nanometer-sized crystals ordering of the grain boundary structure to minimize the interfacial energy does not take place since the curvature of the grain boundary has a much different effect on the energy.

Based on Raman spectroscopy studies on nanocrystalline $\mathrm{TiO}_{2}$ (Melendres et al 1989; Parker and Siegel 1990a, b) and high resolution TEM combined with image simulations on nanocrystalline Pd (Thomas et al 1990; Siegel and Thomas 1992), it was suggested that the grain boundary structures in nanocrystalline materials are no different from those observed in conventional coarse-grained polycrystalline materials (Siegel 1992). By computer simulation methods it was shown that the nanocrystalline grain boundaries contain short-range ordered structural units representative of the bulk material suggesting that the atoms in nanocrystalline materials have sufficient mobility to rearrange themselves into low-energy configurations. Further, since the densities of nanophase materials consolidated from equiaxed clusters extend beyond the $78 \%$ limit for close packing of identical spheres, Siegel (1994) concluded that an extrusion-like deformation of the clusters occurred during the consolidation process. This could occur due to a combination of local deformation and diffusional processes that allow low energy configurations to result. Recent STM observations on nanocrystalline silver and palladium also confirm this hypothesis. Complementing the above results from Raman spectroscopy and small-angle neutron scattering experiments, Siegel and Thomas (1992) concluded that the grain boundaries in nanocrystalline materials and conventional coarse-grained polycrystalline materials have similar structures. Similar conclusions were reached based on observations in nanocrystalline $\mathrm{Cu}$ and $440 \mathrm{C}$ martensitic steel produced by sliding wear (Ganapathi and Rigney 1990), Fe alloys produced by high-energy ball milling (Trudeau et al 1991), and $(\mathrm{Fe}, \mathrm{Mo})_{78} \mathrm{Si}_{9} \mathrm{~B}_{13}$ nanocrystals prepared by crystallization of an amorphous ribbon (Li D X et al 1993). Thus, these data did not reveal any evidence for grain boundary disorder of the type and extent suggested by earlier studies (Gleiter 1989). 
The results of high-resolution TEM have to be interpreted with care (Gleiter 1989). First, electron microscopic characterization of nanocrystalline materials has been done under less than UHV conditions, making the influence of impurities an important consideration. Further, the influence of the high-energy electron beam on the shape and stability of the nanostructures is yet to be defined. Second, since very thin specimens (usually the thickness is less than the crystal diameter) are required for ultra high-resolution TEM, the 3-D crystal arrangement of a bulk nanocrystalline specimen gets transformed into a 2-D arrangement. This process may change the boundary structure as it alters the forces between neighbouring crystals and induces new forces due to the energy of the free surface. Further, due to the high diffusivity in nanocrystalline materials, atoms may diffuse from the free surface of a thin specimen into the grain boundaries at ambient temperatures within a time much shorter than the time for specimen preparation, leading to changes in the boundary structure.

Direct evidence for an accurate structure of the grain boundary is difficult to obtain in view of the relaxation at surfaces; results from FIM and STM may shed new light. Additionally, it would be useful to compare the structure of the grain boundaries in the same material using the same characterization technique, but produced by different methods to resolve some of the conflicting data available in the literature.

\subsection{Grain growth}

Grain growth occurs in polycrystalline materials to decrease the interfacial energy. Since nanocrystalline materials have a highly disordered large interfacial component (and hence they are in a higher energy state), the driving force for grain growth is high. However, contrary to the expectations, experimental observations suggest that the grain growth in nanocrystalline materials, prepared by almost any method, is very negligible up to a reasonably high temperature.

The inherent stability of the nanocrystalline grains has been explained on the basis of structural factors such as narrow grain size distribution, equiaxed grain morphology, low-energy grain boundary structures, relatively flat grain boundary configurations, and porosity present in the samples. Additionally, grain boundary Zener drag and triple junction drag have been found to be significant in retarding grain growth (Lu 1993). In some instances, abnormal grain growth has also been observed (Kumpmann et al 1993; Gertsman and Birringer 1994).

Significant grain growth (doubling of the crystal size in $24 \mathrm{~h}$ ) was observed in single-phase nanocrystalline materials at ambient temperature or below only when the equilibrium melting temperature $T_{\mathrm{m}}$ was lower than about $600^{\circ} \mathrm{C}$ (Birringer 1989). Grain growth was retarded for higher $T_{\mathrm{m}}$ metals, e.g. for $\mathrm{Cu}$ up to $100^{\circ} \mathrm{C}$, for $\mathrm{Pd}$ up to $\sim 250^{\circ} \mathrm{C}$ (Birringer 1989) and for Ti-Mg up to $450^{\circ} \mathrm{C}$ (Suryanarayana and Froes 1992b).

The kinetics of isothermal grain growth in conventional polycrystalline materials can be represented by the equation

$$
d^{2}-d_{0}^{2}=K t
$$

where $d$ is the grain size at time $t, d_{0}$ the mean initial grain size, and $K$ a constant. Theoretical predictions also agree with the above trend. The above equation is obeyed only at temperatures close to the melting point. Assuming that $d \gg d_{0}$, the empirical 
equation

$$
d=K^{\prime} t^{1 / n}
$$

where $K^{\prime}$ is another constant and $n$ the grain-growth exponent, better represents the grain growth behaviour in metals at lower temperatures. $n$ has been found to have values ranging between 2 and 3 . The activation energy for grain growth $Q$, can be calculated from the equation

$$
K^{\prime}=K_{0}^{\prime} \exp (-Q / R T)
$$

Where $K_{0}^{\prime}$ is a pre-exponential constant, and $R$ the gas constant.

Grain growth studies in nanocrystalline materials are difficult since the grain size cannot be determined accurately (Höfler and Averback 1990; Nieman and Weertman 1991). In spite of this, some grain growth studies have been carried out using TEM, differential scanning calorimetry (DSC), X-ray diffraction, and Raman spectroscopy techniques.

Grain growth studies in nanocrystalline materials were conducted by observing the grain size as a function of time at different temperatures, using direct microscopic observations (Höfler and Averback 1990; Boylan et al 1991; Ganapathi et al 1991), or estimated from X-ray diffraction peak broadening values (Lu 1991). Chen and Spaepen (1988) have shown that DSC techniques can be used to determine the parameters that characterize the grain growth process in nanocrystalline materials. The heat released during the growth of the nanometer-sized grains is large enough (due to the high density of interfaces) to be detected by the present-day calorimeters. It is estimated that the heat energy released can be as much as $339 \mathrm{~mJ}$ for a grain size of $5 \mathrm{~nm}$, while it decreases to $0.7 \mathrm{~mJ}$ for a $5 \mu \mathrm{m}$ grain size (Lu 1991).

Crystallization of amorphous alloys obtained by rapid solidification techniques often results in the formation of nanocrystalline grains at relatively low temperatures (Suryanarayana et al 1980). Grain growth studies after crystallization of these glasses was observed and studied by many authors (Lu 1991, 1993; Lu et al 1991b; Spassov and Köster 1993; Suryanarayana and Froes 1993). Grain growth studies have also been performed on nanocrystalline materials produced by sliding wear (Ganapathi et al 1991), inert gas condensation (Höfler and Averback 1990; Kumpmann et al 1993), electrodeposition (Boylan et al 1991), electron gun evaporation (Knauth et al 1993), mechanical alloying (Isonishi and Okazaki 1993; Kawanishi et al 1993) and chemical vapour deposition (Joyce Jr. and Jervis 1988).

Crystallization of metallic glasses takes place generally in two stages, although polymorphic crystallization converts the glassy phase directly into a crystalline phase of the same composition (Ranganathan and Suryanarayana 1985). A stable tetragonal $(\mathrm{Fe}, \mathrm{Co}) \mathrm{Zr}_{2}$ phase forms directly from the ternary $\mathrm{Fe}-\mathrm{Co}-\mathrm{Zr}$ amorphous phase, while in the binary $\mathrm{Fe}-\mathrm{Zr}$ alloys, the amorphous phase first transforms to a metastable $f c c$ $\mathrm{FeZr}_{2}$ phase which later transforms to the equilibrium tetragonal $\mathrm{FeZr}_{2}$ phase. Grain growth studies were performed for both the stable and metastable phases and it was found that the grain size increases with annealing time at temperature (Spassov and Köster 1993). It has also been noted that grain growth starts at a higher temperature in the nanocrystalline sample with smaller grains (Lu 1993) and that grain growth is rapid above a certain temperature and becomes negligible for longer annealing times. Figure 6 shows a plot of the grain size variation with annealing time at different temperatures in an $\mathrm{Al}_{3} \mathrm{Nb}-5 \mathrm{wt} . \% \mathrm{Ti}$ alloy (Kawanishi et al 1993). 


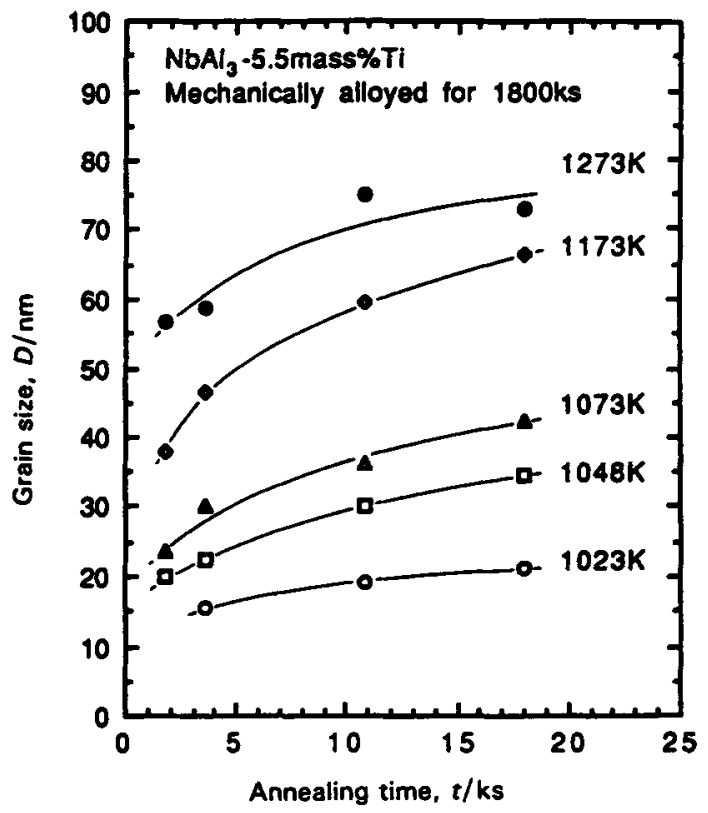

Figure 6. Variation of the mean grain size of the $\mathrm{NbAl}_{3}-5.5 \mathrm{wt} . \% \mathrm{Ti}$ phase as a function of annealing time at different temperatures (Kawanishi et al 1993).

From an analysis of the kinetic data Spassov and Köster (1993) calculated that the grain-growth exponent $\boldsymbol{n}$ has a value of 3 and that the activation energy for grain growth of the $\mathrm{FeZr}_{2}$ phase in a wide temperature range (of about $200^{\circ} \mathrm{C}$ ) was $260 \pm 25 \mathrm{~kJ} \mathrm{~mol}^{-1}$ for both the binary and ternary alloys. Similarly, activation energies of $162 \pm 2 \mathrm{~kJ} \mathrm{~mol}^{-1}$ for $\mathrm{Al}_{3} \mathrm{Nb}$ (Isonishi and Okazaki 1993) and $201 \pm 2 \mathrm{~kJ} \mathrm{~mol}^{-1}$ for $\mathrm{Al}_{3} \mathrm{Nb}-5.5 \mathrm{wt}$.\% $\mathrm{Ti}$ (Kawanishi et al 1993) were reported for grain growth. It may be noted that the grain growth is retarded by Ti additions. The value of $n$ was calculated as 3 for the binary $\mathrm{Al}-\mathrm{Nb}$ alloy, whereas it was estimated to be 4 for the ternary Al-Nb-Ti composition. By measuring the value of $n$, Spassov and Köster (1993) concluded that they were indeed observing crystallization of an amorphous phase rather than grain growth in an extremely fine-grained material.

In most of the studies involving nanocrystalline materials, the value of $n$ is different from the value of 2 deduced from the parabolic relationship for grain growth. Thus, in addition to Zener drag (where a particle interacts with the grain boundary to reduce the energy of the boundary-particle system and restrain the boundary movement), other mechanisms such as pinning of grain boundaries by pores or inclusions also may be operative. The fact that pores (Hahn et al 1990; Höfler and Averback 1990) and impurity doping (Averback et al 1993) have considerable effect on the grain growth characteristics was clearly demonstrated in $\mathrm{TiO}_{2}$. For an initial grain size of $14 \mathrm{~nm}$, when the porosity was about $25 \%$, the grain size after annealing for $20 \mathrm{~h}$ at $700^{\circ} \mathrm{C}$ was $30 \mathrm{~nm}$ (Hahn et al 1990). When the porosity was reduced to about $10 \%$, the grain size for a similar annealing treatment was dramatically increased to $500 \mathrm{~nm}$. The same authors have also demonstrated that sintering the same nanocrystalline material under pressure $(1 \mathrm{GPa})$, or with appropriate dopants such as $\mathrm{Y}$, can suppress the grain growth (figure 7). 


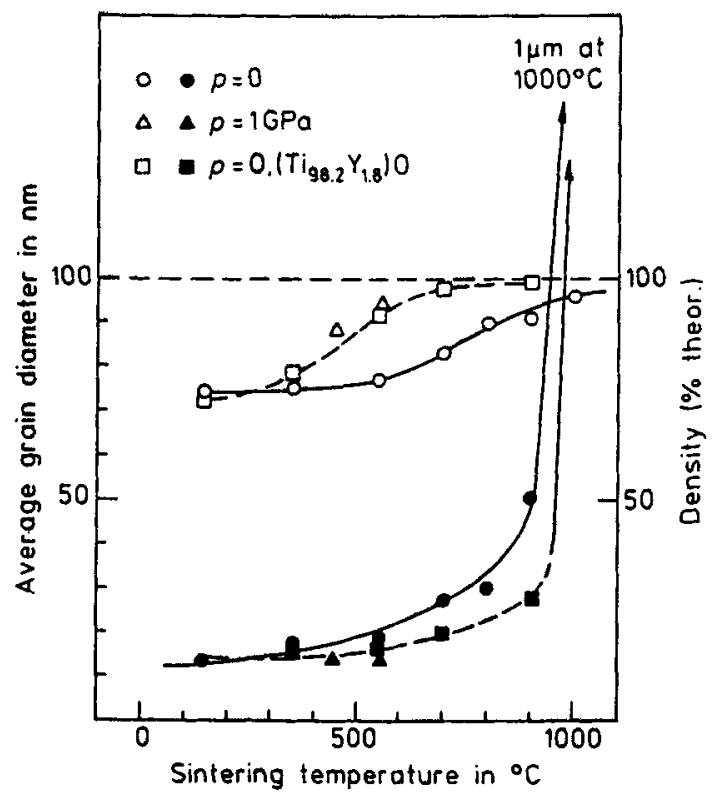

Figure 7. Density (open circles) and grain size (filled circles) of nanocrystalline $\mathrm{TiO}_{2}$ as a function of sintering temperature (Averback et al 1989).

Pinning of grain boundaries in nanocrystals of a $\mathrm{Ni}$ solid solution by the $\mathrm{Ni}_{3} \mathrm{P}$ precipitates in a crystallized Ni-P amorphous alloy (Boylan et al 1991) and segregation of silicon to grain boundaries in a Ni-Si solid solution (Knauth et al 1993) have been found to be responsible for preventing grain growth in nanocrystalline phases. Lu (1993) studied the thermal stability of 7 to $48 \mathrm{~nm}$ grains in a Ni-P alloy and concluded that samples with smaller grains have enhanced thermal stabilities, suggesting that the grain growth temperature and the activation energy for growth in a nanocrystalline state are higher in comparison with coarser grains; attributed to the configuration and energetic state of the interfaces in the nanocrystalline materials.

Ganapathi et al (1991) tried to fit their grain growth data on nanocrystalline $\mathrm{Cu}$ produced by sliding wear and observed an excellent fit for all values of $n=2,3$, or 4 . Thus, they concluded that it is difficult to identify a grain growth mechanism on the basis of the exponent $n$ alone, and that grain growth in nanocrystalline materials probably occurs in a manner similar to that in conventional polycrystalline materials.

Abnormal grain growth has been observed at room temperature or slightly above in some instances e.g. $\mathrm{Cu}, \mathrm{Ag}$, and Pd (Kumpmann et al 1993; Gertsman and Birringer 1994). Similar to the observation of Hahn et al (1990), Gertsman and Birringer (1994) also noted that grain growth occurs preferentially in the denser material. This anomalous grain growth has been suggested to be due to (i) a certain non-uniformity of the grain size distribution in the as-prepared samples so that the larger grains act as nuclei and (ii) impurity segregation. If the impurity distribution is spatially non-uniform, enhanced grain growth may occur in regions of lowest impurity content. The reason why such abnormal grain growth does not occur in coarse-grained polycrystalline materials has been attributed to the enhanced grain boundary enthalpy (leading to high driving force) and/or non-equilibrium grain boundary structure (leading to increased mobility of grain boundaries) in the nanocrystalline state. 


\section{GRAIN SIZES OF Ti-24AI-11Nb HIP'ed AT DIFFERENT TEMPERATURES}
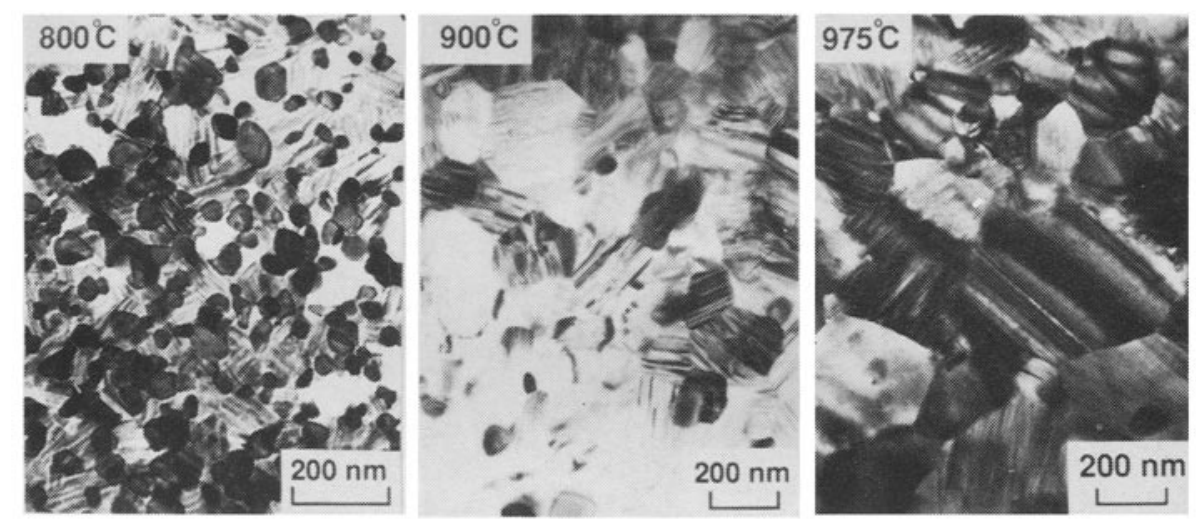

Figure 8. Electron micrographs of mechanically alloyed $\mathrm{Ti}-24$ at. $\% \mathrm{Al}-11$ at. $\% \mathrm{Nb}$ powders hot isostatically pressed $\left(207 \mathrm{MPa}, 2 \mathrm{~h}\right.$ ) at (a) $800^{\circ} \mathrm{C}$, (b) $900^{\circ} \mathrm{C}$, and (c) $975^{\circ} \mathrm{C}$ (Suryanarayana et al 1994).

Grain growth can also occur in nanocrystalline materials during consolidation of the powder, which requires exposure of the powder to high temperatures and pressures for extended periods of time. Consolidation of nanocrystalline powders has been achieved by electro-discharge compaction (Okazaki 1993), plasma-activated sintering (Groza 1994), shock consolidation (Korth 1993), and hot-isostatic pressing (Suryanarayana et al 1993). Optimization of the consolidation parameters is important because retention of the nanostructures requires low consolidation temperatures while achieving of full (theoretical) density requires high temperatures. However, because nanocrystalline materials resist grain growth, grain coarsening has not been a serious concern in the consolidated materials. Figure 8 shows a series of electron micrographs of a Ti-24at. $\% \mathrm{Al}-11 \mathrm{at} . \% \mathrm{Nb}$ powders of $15 \mathrm{~nm}$ grain size produced by mechanical alloying and consolidated by hot-isostatic pressing at $800^{\circ} \mathrm{C}, 900^{\circ} \mathrm{C}$, and $975^{\circ} \mathrm{C}$ at a pressure of $207 \mathrm{MPa}$ for $2 \mathrm{~h}$. It may be noted that the grain sizes are only $50 \mathrm{~nm}$ at $800^{\circ} \mathrm{C}$ and $125 \mathrm{~nm}$ at $975^{\circ} \mathrm{C}$. A similar situation was obtained in the Ti-55at. $\% \mathrm{Al}$ samples mechanically alloyed to an amorphous state and hot isostatically pressed at the above temperatures; in fact, the grain sizes are finer in this case (Suryanarayana et al 1994).

\section{Properties}

Because of the very fine grain sizes, nanocrystalline materials exhibit a variety of properties that are different and often considerably improved in comparison with those of conventional coarse-grained polycrystalline materials. These include increased strength/hardness, enhanced diffusivity, improved ductility/toughness, reduced density, reduced elastic modulus, higher electrical resistivity, increased specific heat, higher thermal expansion coefficient, lower thermal conductivity, and superior soft magnetic 
properties in comparison to conventional coarse-grained materials. All of these properties are being extensively investigated to explore possible applications. In the present article, we shall discuss the origin and consequences of some of these properties.

\subsection{Diffusion and sinterability}

Since nanocrystalline materials contain a very large fraction of atoms at the grain boundaries, the numerous interfaces provide a high density of short-circuit diffusion paths. Consequently, they are expected to exhibit an enhanced diffusivity in comparison to single crystals or conventional coarse-grained polycrystalline materials with the same chemical composition (Horvath et al 1987; Birringer et al 1988; Hahn et al 1989; Horvath 1989; Schumacher et al 1989). This enhanced diffusivity can have a significant effect on mechanical properties such as creep and superplasticity, ability to efficiently dope the nanocrystalline materials with impurities at relatively low temperatures, and synthesis of alloy phases in immiscible metals and at temperatures much lower than those usually required in other systems.

The measured diffusivities in nanocrystalline copper are about 14 to 20 orders of magnitude higher than lattice diffusion and about 2 to 4 orders of magnitude larger than grain boundary diffusion. For example, the measured diffusivity at room temperature is $2.6 \times 10^{-20} \mathrm{~m}^{2} / \mathrm{s}$ for $8 \mathrm{~nm}$-grain sized copper samples compared to $4.8 \times 10^{-24}$ for grain boundary diffusion and $4 \times 10^{-40}$ for lattice diffusion (Schumacher et al 1989). Similarly enhanced diffusivities were also observed for solute diffusion in other metals. However, it was noted (Mütschele and Kirchheim 1987a) that hydrogen segregation at grain boundaries in Pd had to be described by a spectrum of site energies or segregation energies. This causes the diffusion coefficient to become concentration-dependent, being lower than the single-crystal value at low hydrogen concentrations and higher for high hydrogen concentrations. The enhanced self- and impurity-diffusivities in nanocrystalline materials appear to be strongly linked to the porosity present in the samples. Averback et al (1989) showed that diffusion could be suppressed back to conventional values by sintering the samples to full density.

The increased diffusivity (and consequently the reactivity) leads to increased solid solubility limits, formation of intermetallic phases (at temperatures much lower than those required for coarse-grained materials and sometimes new phases) and increased sinterability of nanocrystalline powders.

Solid solubility limits are usually enhanced when the material is in the nanocrystalline state. In extreme cases, solid solutions can also form in alloy systems which exhibit miscibility gaps both in the liquid and solid states. Typical examples of this phenomenon are the $\mathrm{Ag}-\mathrm{Fe}$ (Shingu et al 1988) and $\mathrm{Ti}-\mathrm{Mg}$ (Suryanarayana and Froes 1990) systems. While the solid solubility of $\mathrm{Mg}$ in $\mathrm{Ti}$ under equilibrium conditions is $<0.2$ at. $\%$, it could be increased to 6 at. $\%$ when titanium grains are in the nanometer range. Similarly, the solid solubility of $\mathrm{Bi}$ in $\mathrm{Cu}$ is $<10^{-4}$ at.\% under equilibrium and this has been increased to 4 at.\% in the nanocrystalline state (Birringer et al 1988). A dramatic example is the achievement of 17 at. $\%$. (40 wt.\%) solubility of $\mathrm{Hg}$ in nanocrystalline $\mathrm{Cu}$, against an equilibrium value of $<1$ at.\% (Ivanov 1992). The enhanced solid solubility limits in these systems have been explained on the basis of elastic strains at the interfaces; demonstrated to be the reason both theoretically 
and experimentally for various alloys earlier. Thus, nanostructure processing appears to be a novel way of forming solid solution alloys in systems in which alloying has not been possible by any other technique.

The high diffusivity and reactivity of nanocrystalline materials results in alloying by diffusion along the grain boundaries resulting in the formation of stable and metastable phases at relatively low temperatures. For example, formation of the $\mathrm{Pd}_{3} \mathrm{Bi}$ intermetallic has been found to occur at $120^{\circ} \mathrm{C}$, a temperature much lower than normally observed (Siegel and Hahn 1987). Similarly, nanocrystalline mixtures of copper and erbium crystallites formed the equilibrium $\mathrm{CuEr}$ compound by compaction (Siegel and Hahn 1987). Li et al (1988a) detected two new polymorphs of erbium oxide in the nanocrystalline state.

Another important consequence of the increased diffusivity is that sintering of nanocrystalline powders can occur at temperatures lower than those required for sintering coarse-grained polycrystalline powders. Significant improvements in the sinterability and mechanical properties (hardness and fracture characteristics) of $\mathrm{TiO}_{2}$ have been obtained in nanocrystalline $\mathrm{TiO}_{2}$ (rutile) in comparison to conventionally synthesized coarse-grained rutile (Siegel et al 1988; Hahn et al 1990; Mayo et al 1990). For example, $\mathrm{TiO}_{2}$ with a grain size for $12 \mathrm{~nm}$ could be sintered at ambient pressures at temperatures 400 to $600^{\circ} \mathrm{C}$ lower than that required for ball-milled $1.3 \mu \mathrm{m}$ powder (figure 9), and without the need for any compacting or sintering aid, such as polyvinyl alcohol, which is usually required. Additionally, the fracture characteristics of sintered nanocrystalline $\mathrm{TiO}_{2}$ appear to be significantly different from those of sintered commercial powder. The sintering temperature for transgranular fracture of nanocrystalline $\mathrm{TiO}_{2}\left(12 \mathrm{~nm}\right.$ grain size) has been shown to be $200^{\circ} \mathrm{C}$ lower than that for sintered commercial coarse-grained $(1.3 \mu \mathrm{m}$ grain size) powder. Further, the sintered nanocrystalline material had smaller and fewer voids than the commercial

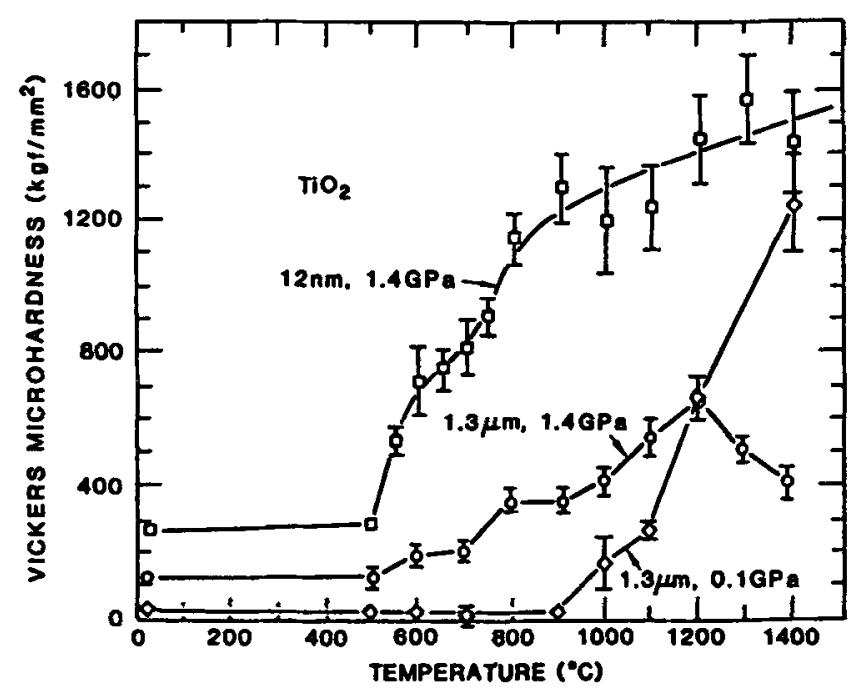

Figure 9. Vickers microhardness of $\mathrm{TiO}_{2}$ (rutile) measured at room temperature as a function of one-half hour sintering at successively increased temperatures. Note that rutile with a $12 \mathrm{~nm}$ grain size sinters at temperatures $400^{\circ} \mathrm{C}$ to $600^{\circ} \mathrm{C}$ lower than coarse-grained $(1 \cdot 3 \mu \mathrm{m})$ rutile (Siegel et al 1988$)$. 
material (Li et al 1988b). Reduced sintering temperatures for achieving full density were also observed in nanocrystalline titanium aluminide intermetallics (Suryanarayana et al 1993, 1994) and thus it may be a general phenomenon. It is not surprising that nanocrystalline materials, with their ultrafine grain sizes (and possibly clean particle surfaces and high grain boundary purity), will sinter at much lower temperatures than conventional coarse-grained materials. However, it is interesting that they retain the ultrafine grain size after sintering to full density.

\subsection{Mechanical properties}

The elastic constants of nanocrystalline materials have been found to be reduced by $30 \%$ or less. These results were interpreted as due to the large free volume of the interfacial component resulting from the increased average interatomic spacings in the boundary regions (Gleiter 1989). The reduction in Young's modulus values was interpreted by others (Nieman et al 1991b; Krstic et al 1993) to be due to the level of porosity and state of cracks in the samples.

The most significant change resulting from a reduction in the grain size to the nanometer level is a 4-5 times increase in the strength and hardness over the coarsegrained material. This is also the least understood and most controversial area. While the $0.2 \%$ yield strength of a $14 \mathrm{~nm}$ grain size Pd sample was reported to be $250 \mathrm{MPa}$, that of a sample with a $50 \mu \mathrm{m}$ grain size was only $52 \mathrm{MPa}$ (figure 10) (Nieman et al. 1990). Similar results were reported by others in Pd (Fougere et al 1992; S Li et al 1993) and other pure metals Cu (Nieman et al 1991b; Fougere et al 1992; Le Brun et al 1992), Ni (Hughes et al 1986; El-Sherik et al 1992; Le Brun et al 1992), Fe (Jang and Koch 1990; Le Brun et al 1992), Ti (K Y Wang et al 1993), Ag (Nieman et al 1991a), intermetallic compounds $\mathrm{Nb}_{3} \mathrm{Sn}$ (Cho and Koch 1991), $\mathrm{Ni}_{3} \mathrm{Al}$ (Jang and Koch 1988), TiAl (Chang et al 1992; Suryanarayana et al 1994), $\mathrm{Ti}_{3} \mathrm{Al}$ (Suryanarayana et al 1994); $\mathrm{Al}_{3} \mathrm{Nb}$ (Kim and Okazaki 1992), Ni-P (S Li et al 1993: McMahon and Erb 1989), Fe-B-Si (Tong et al 1992), $\mathrm{Fe}-\mathrm{Mo}-\mathrm{Si}-\mathrm{B}$ (Liu et al 1993a), and $\mathrm{TiO}_{2}$ samples

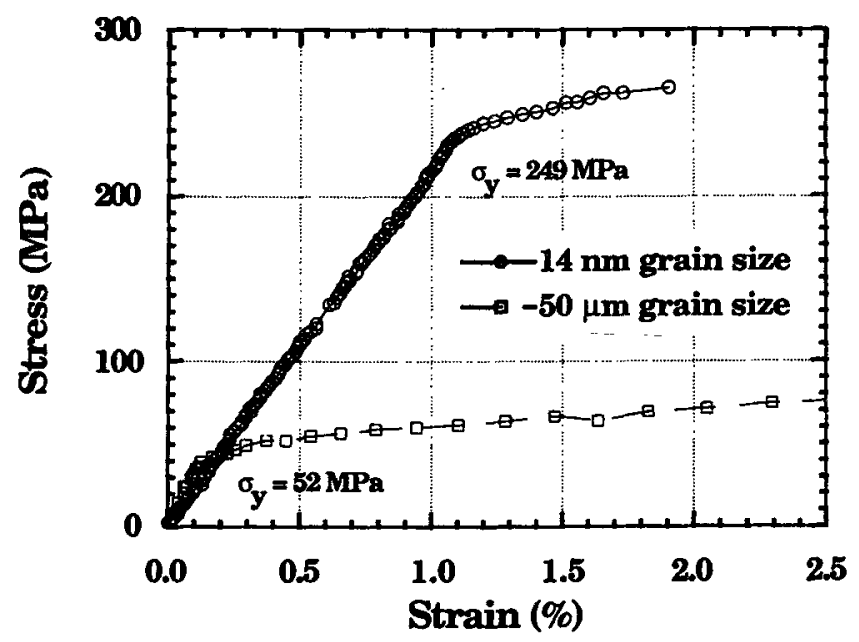

Figure 10. Stress-strain curves for nanocrystalline $(14 \mathrm{~nm})$ and coarse-grained $(50 \mu \mathrm{m})$ palladium samples. The strain rate is $2 \times 10^{-5} \mathrm{~s}^{-1}$ (Nieman et al 1990). 
(Höfler and Averback 1990). A reduction in hardness with grain size was, however, reported for $\mathrm{Cu}$ and Pd samples by Chokshi et al (1989) and for $\mathrm{Ni}-\mathrm{P}$ by Lu et al (1990).

The Hall-Petch relationship (Hall 1951; Petch 1953) for conventional coarse-grained polycrystalline materials suggests that the yield strength (or hardness) of a material increases with a decreasing grain size according to the relationship

$$
\sigma=\sigma_{0}+K d^{n}
$$

where $d$ is the grain size, $\sigma$ the $0.2 \%$ yield strength (or hardness), $\sigma_{0}$ the lattice friction stress to move individual dislocations (or the hardness of a single crystal specimen), $n$ the grain size exponent (generally $-1 / 2$ ), and $K$ a constant. Accordingly, nanocrystalline materials are expected to show a much higher yield strength than the coarse-grained materials of the same composition. However, it should be realized that the above equation has certain limitations. First, the strength value cannot increase indefinitely to beyond the theoretical strength limit. Second, any relaxation process taking place at the grain boundaries (due to the very fine grain size) could lead to a decrease in strength and, thus, an inverse Hall-Petch relationship (decrease in strength with a decrease in grain size) could result below some critical grain size. Third, the Hall-Petch relationship was derived on the basis of strengthening due to dislocation pile-ups at physical obstacles. At extremely fine grain sizes, e.g. in the nanometer regime, the individual grains cannot support more than one dislocation; and thus, the Hall-Petch relationship may not be valid. Thus, it is logical to expect that the mechanism of hardening/softening observed in nanocrystalline materials may be fundamentally different from that observed in coarser grained metals.

Recently, there has been an active debate in the literature on the origin of the high strengths of nanocrystalline materials, and attempts have been made to modify the Hall-Petch relationship to explain the observed results. Before we discuss the modifications, it may be useful to summarize the results on the variation of hardness (there are very few reports of yield strength measurements on materials with a grain size of $<100 \mathrm{~nm}$ ) with grain size.

(1) Generally, the hardness increases with a decrease in grain size.

(2) At very small grain sizes, the hardness decreases with a decrease in grain size, referred to as the inverse Hall-Petch relationship. The critical grain size at which this reversal takes place is dependent on the material. In some materials, the hardness increases linearly with $d^{-1 / 2}$ and then reaches a plateau at small grain sizes.

(3) The Hall-Petch slope $K$ is much smaller in the nanometer range than is observed at more normal grain sizes.

(4) Annealing a sample to produce grain growth resulted in hardness values greater than those of as-prepared samples with similar grain sizes.

Let us now look at the possible reasons for the deviation from the Hall-Petch relationship in nanocrystalline materials. The Hall-Petch relationship was derived using the concept of dislocation pile-ups in individual grains (Armstrong 1983). However, since in very fine-grained materials, e.g. nanocrystalline materials, pile-ups cannot form when the grain size is less than a critical value $l_{c}$ (Gryaznov et al 1990), weakening mechanisms (e.g. viscous type flow) operate and lead to a decrease in hardness with decreasing grain size, i.e. a negative value for the slope $K(\mathrm{Nieh}$ and Wadsworth 1991). The value of $l_{c}$ can be calculated by equating the repulsive force 
between the dislocations and the applied stress using the relation

$$
l_{c}=\frac{3 G b}{\pi(1-v) H},
$$

where $G$ is the shear modulus, $b$ the Burgers vector, $v$ the Poisson's ratio, and $H$ the hardness.

The above model could explain the reversal in hardness with grain size in nanocrystalline $\mathrm{Cu}$ and $\mathrm{Pd}$. The negative slope in $\mathrm{Ni}-\mathrm{P}$ has been explained on the basis of the precipitation hardening due to the formation of $\mathrm{Ni}_{3} \mathrm{P}$ on thermal annealing. However, this reasoning does not explain all of the results (Suryanarayana et al 1992). A more convincing explanation for the negative slope can be offered by taking into account the volume fraction of triple junctions (Palumbo et al 1990a; Suryanarayana et al 1992; El-Sherik et al 1992), since it has been earlier reported (Rabukhin 1986) that an increased triple junction volume fraction leads to softening and enhanced bulk ductility in polycrystalline materials.

Many investigators now accept that there exists a critical grain size in nanocrystalline materials above which the Hall-Petch slope is positive and below which it is negative; different reasons have been put forward for its presence. According to Palumbo et al (1990a), the transition from a positive to a negative slope occurs when the triple junctions in the microstructure begin to comprise a significant volume fraction of the bulk specimen value. Fougere et al $(1992,1993)$ and Liu et al (1993b) observed that the hardening or softening of nanocrystalline materials can depend on the method used to vary the grain size. Annealing a sample to produce grain growth resulted in hardness values greater than those of as-prepared samples with similar grain sizes. Lu and Sui (1993), on the other hand, felt that thermal annealing of the as-prepared sample will relax the interfacial structure leading to a reduction in interfacial excess energy and this could explain the abnormal Hall-Petch behaviour.

Unlike the situation in equiaxed nanocrystalline materials, the Hall-Petch-type relationship appears to be obeyed always with a positive slope in layered nanocrystalline materials when the microhardness is plotted as a function of the layer thickness. This observation has been verified in vacuum-deposited Al-2 to $15.3 \mathrm{wt} . \%$ Fe alloys with the Fe layer spacing varying between 0.2 and $2.9 \mathrm{~nm}$ (Bickerdike et al 1984-85) and also in Cu-15 to $60 \mathrm{wt} \%$ Fe alloys (Palatnik et al 1967). The layer thickness here is defined as the sum of the individual layer thicknesses of the constituent metals. However, it should be remembered that hardness values have been measured for layer thicknesses of 24 to $2000 \mathrm{~nm}$ only, which are considerably larger than the sizes at which a transition in the Hall-Petch slope is expected to occur. It will be interesting to produce layered nanocrystals with a layer thickness of about $10 \mathrm{~nm}$ or less and see whether the Hall-Petch slope is negative in this range. A critical discussion on the origins of strengthening and also the supermodulus effect in 1-D layered nanocrystalline materials can be found in Suryanarayana and Froes (1992a).

Apart from the sign of the Hall-Petch slope, there are also reports that the grain size exponent $n$ can have very different values (i.e. the traditional Hall-Petch equation may not be valid at all). Christman (1993) presents data for both coarse and nanograined polycrystalline materials to show that the yield strength/hardness variation with gain size can be equally well explained assuming that $n=-1,-1 / 2,-1 / 3$ and $-1 / 4$. Each of these values, obtained from theoretical estimates, is based on different 
mechanisms and/or modelling for dislocation-grain boundary interaction mechanisms. Christman (1993) also suggests that a correspondence could exist between the crystal structure and $n$. Assuming that the dislocation pile-up model is valid even in nanocrystalline materials, Pande et al (1993) considered the effect of a smaller number of dislocations in the pile-up and also the effect of anisotropy and suggested that the grain size exponent could be modified from the traditional value of $-1 / 2$. Other investigators have modified the normal Hall-Petch equation by modifying either the grain size exponent and/or the slope of the plot, $K$. Different values of $K$ have also been reported above and below the critical grain size (Scattergood and Koch 1992; Gryaznov et al 1993; Lian and Baudelet 1993; Li S et al 1993).

\subsection{Ductilization of ceramics and intermetallics}

The fine grain sizes and the high rates of diffusivity observed in the nanocrystalline materials suggest that considerable ductility can occur in these materials even at room temperature. This follows from the expression for strain rate, $\mathrm{d} \varepsilon / \mathrm{d} t$ during diffusional creep

$$
\frac{d \varepsilon}{d t}=\frac{\sigma \Omega}{d^{2} k T}\left(B_{1} D_{v}+\frac{B_{2} \Delta D_{b}}{d}\right),
$$

where $\sigma$ is the applied stress, $\Omega$ the atomic volume, $d$ the grain size, $k$ the Boltzmann constant, $T$ the temperature, $B_{1}$ and $B_{2}$ are constants, $D_{v}$ and $D_{b}$ are, respectively, the volume and grain boundary diffusion coefficients, and $\Delta$ the grain boundary width. At low temperatures, where boundary diffusion dominates, $d \varepsilon / d t$ can be rewritten (Coble 1963) as:

$$
\frac{d \varepsilon}{d t}=\frac{B_{2} \sigma \Omega \Delta D_{b}}{d^{3} k T} .
$$

Thus, the diffusional creep rate of a polycrystalline sample is increased by reducing the grain size and/or by increasing the grain boundary diffusivity. The grain size of nanocrystalline materials is reduced by three orders of magnitude compared to conventional polycrystalline materials (from about $10 \mu \mathrm{m}$ to $10 \mathrm{~nm}$ ), and the boundary diffusivity is higher by three orders of magnitude. Accordingly, nanocrystalline ceramic and intermetallic compounds are generally expected to exhibit a 12 orders of magnitude increase in diffusional creep. And this has, in fact, been observed (Karch et al 1987) when nanocrystalline $\mathrm{CaF}_{2}$ and $\mathrm{TiO}_{2}$ deform plastically at room temperature. However, there have not been any reports of the expected dramatically increased ductility in nanocrystalline intermetallic compounds.

Recent nanoindenter measurements on $12 \mathrm{~nm}-\mathrm{TiO}_{2}$ (Mayo et al 1990) and $7 \mathrm{~nm}-\mathrm{ZnO}$ (Mayo et al 1992) have demonstrated that the strain-rate sensitivity increases dramatically to about 0.04 , approximately one-quarter that for lead at room temperature. However, no superplasticity has yet been observed in nanocrystalline materials at room temperatures, which would yield strain-rate sensitivity values about an order of magnitude higher than the maximum so far observed. Nevertheless, superplastic behaviour is expected to be exhibited by these ultrafine-grained materials at least at elevated temperatures (Guermazi et al 1991). 
The enhanced strain rate sensitivity appears to arise due to a combination of several factors-grain boundary sliding, presence of porosity, ultrafine grain size and rapid short-range diffusion. These can lead to enhanced formability of intermetallics, ceramics and semiconductors. It has been recently demonstrated that near-net shape forming of nanocrystalline $\mathrm{TiO}_{2}$ can be achieved at $800-900^{\circ} \mathrm{C}$ with excellent detail (Karch and Birringer 1990).

The fine grain size and its effect on improved forming characteristics is an advantage for many structural materials. However, the ultrafine-grain size may not be compatible with good elevated-temperature creep performance. A way out of this dilemma can be that the nanostructured grains can be used to enhance processing (forming) and the grain size of the final product could be subsequently increased using a suitable heat treatment.

It should be realized that enhanced ductility (and hence formability) is generally associated with low hardness (and strength) and the presence of sufficient number of slip systems to satisfy the von Mises criterion for plasticity. Since nanocrystalline materials are very hard (and strong), it is doubtful whether the formability can be substantially improved, especially in non-cubic intermetallic compounds. This may, however, be possible if the mechanisms of deformation in nanocrystalline materials are entirely different from those in conventional coarse-grained polycrystalline materials. Irrespective of the reasons for the high strength of nanocrystalline materials, several investigations are being conducted to optimize the strength and ductility of these materials. It has been noted that a uniform dispersion of about $20 \mathrm{vol} \%$ of a nanocrystalline phase in an amorphous matrix increases the strength of the material significantly while maintaining an adequate level of ductility in the composite (figure 11) (Masumoto 1994). This appears to be a fruitful line of research investigation.

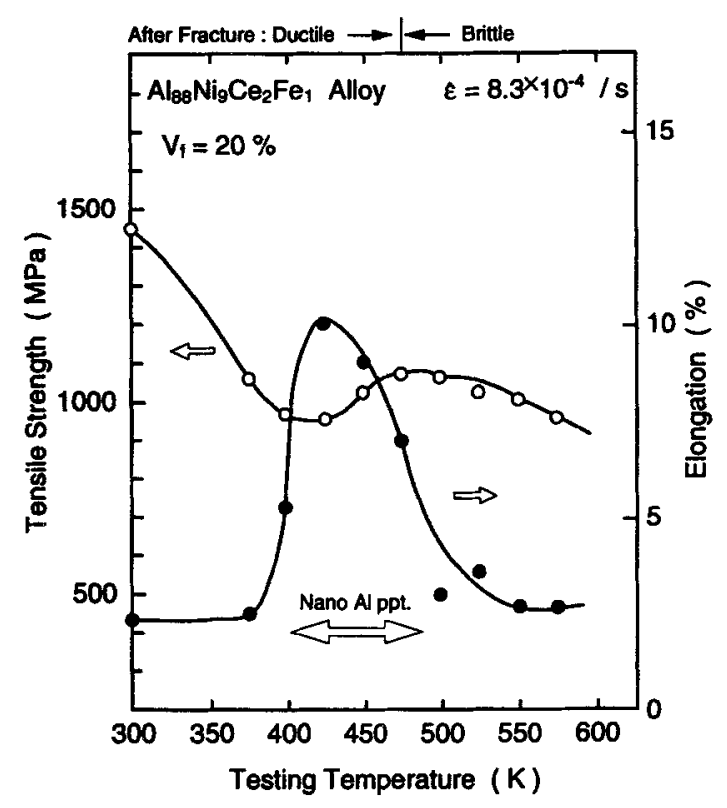

Figure 11. Tensile strength and elongation as a function of test temperature for $\mathrm{Al}_{88} \mathrm{Ni}_{9} \mathrm{Ce}_{2} \mathrm{Fe}_{1}$ alloy with 20 vol.\% of nanocrystalline $\alpha$-Al dispersions (Masumoto 1994). 
Metals are usually soft, ductile and tough while ceramics are strong, hard and brittle. However, through nanostructure processing, it appears to be possible to make metals hard and strong like ceramics and ceramics can be made ductile like metals.

\subsection{Electrical properties}

Because of the increased volume fraction of atoms lying at the grain boundaries, the electrical resistivity of nanocrystalline materials is expected to be higher than that in the corresponding coarse-grained polycrystalline materials. Actual measurements of electrical resistivity on the nanocrystalline materials have been carried out only recently.

The electrical resistivity, $\rho$, of nanocrystalline materials has been found to be higher than that in both coarse-grained polycrystalline metals and amorphous alloys. Y Z Wang et al (1993) and Liu et al $(1993 b, 1994)$ measured $\rho$ at room temperature for an amorphous alloy of $\left(\mathrm{Fe}_{99} \mathrm{Cu}_{1}\right)_{78} \mathrm{Si}_{9} \mathrm{~B}_{13}$ composition as $102 \mu \Omega \mathrm{cm}$; after crystallization to a grain size of $30 \mathrm{~nm}, \rho$ was $126 \mu \Omega \mathrm{cm}$. A similar behaviour was reported in Ni-P alloys (Lu et al 1991a, 1992). $\rho$ of nanocrystalline metals $\mathrm{Cu}, \mathrm{Pd}$ and $\mathrm{Fe}$ prepared by the gas condensation method (Gleiter 1989), and $\mathrm{Ni}$ by electrodeposition (Bakonyi et al 1993) was also measured, showing values higher than that in the coarse-grained material.

From the variation of $\rho$ with temperature and grain size, the following conclusions can be drawn:

(i) $\rho$ is proportional to the temperature for different grain sizes and in a wide temperature range (Lu et al 1991a; Wang Y Z et al 1993).

(ii) At a constant temperature, $\rho$ increases with a decreasing grain size (figure 12).

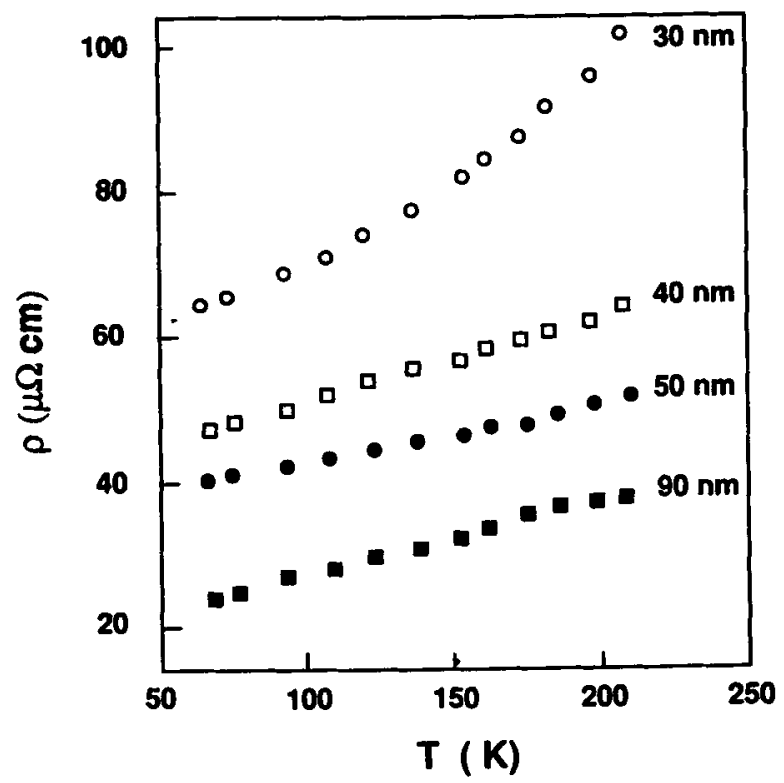

Figure 12. Variation of electrical resistivity with temperature for nanocrystalline $\mathrm{Fe}-\mathrm{Cu}-\mathrm{Si}-\mathrm{B}$ alloys (Y Z Wang et al 1993). 
For example, for the Fe-Cu-Si-B nanocrystalline alloy, $\rho$ is $126 \mu \Omega \mathrm{cm}$ for a grain size of $30 \mathrm{~nm}$ and decreases to $44 \mu \Omega \mathrm{cm}$ at $90 \mathrm{~nm}$ (Wang Y Z et al 1993).

(iii) The residual resistivity at $0 \mathrm{~K}$ decreases with an increasing grain size and this has been correlated with the variation of interfacial volume fraction with the grain size (Lu et al 1991a).

(iv) The temperature coefficient of electrical resistivity has been found to decrease with a decreasing grain size ( $\mathrm{Lu}$ et al 1991a).

All of the above conclusions are consistent with the theoretical analysis of scattering of electrons by grain boundaries. If the crystal size is smaller than the electron mean free path, grain boundary scattering dominates and hence the electrical resistivity as well as the temperature coefficient are expected to increase. A negative temperature coefficient of resistivity is frequently observed in amorphous alloys (Suryanarayana 1984); this has not been reported in nanocrystalline materials even though it has been predicted (Reiss et al 1986).

It has also been shown (Siegel 1991b) that the AC conductivity of nanocrystalline $\mathrm{TiO}_{2}$ doped with about $1 \% \mathrm{Pt}$ is reversible with temperature. This reversibility has been ascribed to the $\mathrm{Pt}$ doping into the band gap of this wide-band-gap $(3.2 \mathrm{eV})$ semiconductor. The easy doping possibility of nanocrystalline electroceramics may lead to a wide range of interesting device applications.

The magnitude of the electrical resistivity (and hence conductivity) in composites can be changed by altering the size of the electrically conducting component. For example, by changing the size of the iron particles and the volume fraction occupied by iron, the electrical properties can be varied in a continuous fashion in an iron-silica system. By changing the volume fraction alone, the electrical conductivity could be increased by 14 orders of magnitude.

The phenomenon of giant magnetoresistance (GMR) (decrease of electrical resistance of materials when exposed to a magnetic field) has been reported in a number of multilayer systems (Baibich et al 1988). GMR has been recently observed in equiaxed (3-D) nanocrystalline materials (Berkowitz et al 1992; Xiao et al 1992). Whereas the resistance drop is only 1 to $2 \%$ in conventional coarse-grained materials, the drop is as large as 50 to $80 \%$ in the case of nanocrystalline materials. GMR has been shown to occur in magnetically inhomogeneous media containing nonaligned ferromagnetic entities on a microscopic scale and scales inversely with the average particle diameter.

\subsection{Specific heat}

Since the specific heat of a material is directly related to the atomic structure, measurements of the specific heat as a function of temperature of nanocrystalline materials should reveal differences in comparison to glassy or crystalline materials of comparable chemical composition. Specific heat measurements have been made on nanocrystalline materials prepared by the gas condensation (Rupp and Birringer 1987), mechanical alloying (Hellstern et al 1989), and crystallization of amorphous alloys prepared by rapid solidification methods (Lu et al 1991c).

Table 3 compares the specific heats of different nanocrystalline materials with their coarse-grained polycrystalline counterparts, and also with an amorphous material of the same composition, wherever available. It may be noted that the specific heat in the nanocrystalline state is much higher than that in the coarse-grained material (by 
Table 3. Comparison of specific heats $(\mathrm{J} / \mathrm{mol} \mathrm{K})$ of nanocrystalline, amorphous, and coarse-grained polycrystalline materials measured at $250 \mathrm{~K}$.

\begin{tabular}{lccc}
\hline Material & Nanocrystalline & Amorphous & $\begin{array}{l}\text { Coarse-grained } \\
\text { polycrystalline }\end{array}$ \\
\hline $\mathrm{Cu}$ & 26 & - & 24 \\
$\mathrm{Pd}$ & 37 & $27^{*}$ & 24 \\
$\mathrm{Ni}-20 \mathrm{at} \% \mathrm{P}^{* *}$ & 25 & 24 & 22 \\
\hline
\end{tabular}

* Extrapolated to pure $\mathrm{Pd}$ based on the values for amorphous $\mathrm{Pd}_{72} \mathrm{Si}_{18} \mathrm{Fe}_{10}$

** Measured in the temperature range of 310 to $400 \mathrm{~K}$.

as much as $50 \%$ in some cases) and of even the amorphous material. While most of the investigators (Rupp and Birringer 1987; Hellstern et al 1989) reported a nonlinear (parabolic) variation of specific heat with temperature, Lu et al (1991c) reported a linear variation. Hellstern et al (1989) also noted that the specific heat increase at a constant temperature was linear with the reciprocal crystal size.

The specific heat of a material is closely related to its vibrational and configurational entropy, which is significantly affected by the nearest-neighbour configurations. Thus, the increase in specific heat of nanocrystalline materials has been attributed to the small crystal size (and consequent large interfacial component). If this is so, grain growth should reduce the specific heat of the nanocrystalline material. This was, in fact, observed (Rupp and Birringer 1987; Hellstern et al 1989).

\subsection{Thermal expansion}

Measured thermal expansion coefficients, $\alpha$, of nanocrystalline $\mathrm{Cu}, \mathrm{Pd}, \mathrm{Fe}-\mathrm{B}-\mathrm{Si}$ and $\mathrm{Ni}$-P alloys were almost twice the value for single crystals (Birringer 1989; Lu et al 1991c, 1992; Tong et al 1992). For example, $\alpha$ for nanocrystalline $(8 \mathrm{~nm}) \mathrm{Cu}$ has been reported to be $31 \times 10^{-6} \mathrm{~K}^{-1}$ in comparison with $16 \times 10^{-6} \mathrm{~K}^{-1}$ for copper single crystals (Birringer 1989). Similar enhancements were observed in nanocrystalline $\mathrm{Pd}, \mathrm{Ni}-\mathrm{P}, \mathrm{Fe}_{78} \mathrm{~B}_{13} \mathrm{Si}_{9}$ and $\mathrm{TiO}_{2}$ samples. As the crystalline component for a nanocrystalline material contributes insignificantly to the enhancement of $\alpha$, the average $\alpha$ of the boundary component has been proposed to be about $60 \times 10^{-6} \mathrm{~K}^{-1}$; agreeing with direct measurements (Klam et al 1987). Thus, by varying the interfacial volume (by changing the grain size), one can 'tailor' the coefficient of thermal expansion to any predetermined value.

\subsection{Optical properties}

Only a limited amount of information is available on the optical properties of nanocrystalline materials. In spite of this, the results are interesting and show that the optical transparency can be changed by controlling the processing parameters.

Figure 13 shows two ceramic $\mathrm{Y}_{2} \mathrm{O}_{3}$ samples synthesized by the gas-phase condensation technique. Even though both the samples have approximately the same grain and pore size $(8 \mathrm{~nm})$, the sample on the right is transparent, while the one on the left is opaque. The reason for the different transparencies is that there is very little aggregation between the nanocrystals in the specimen on the right; accordingly, the pores 


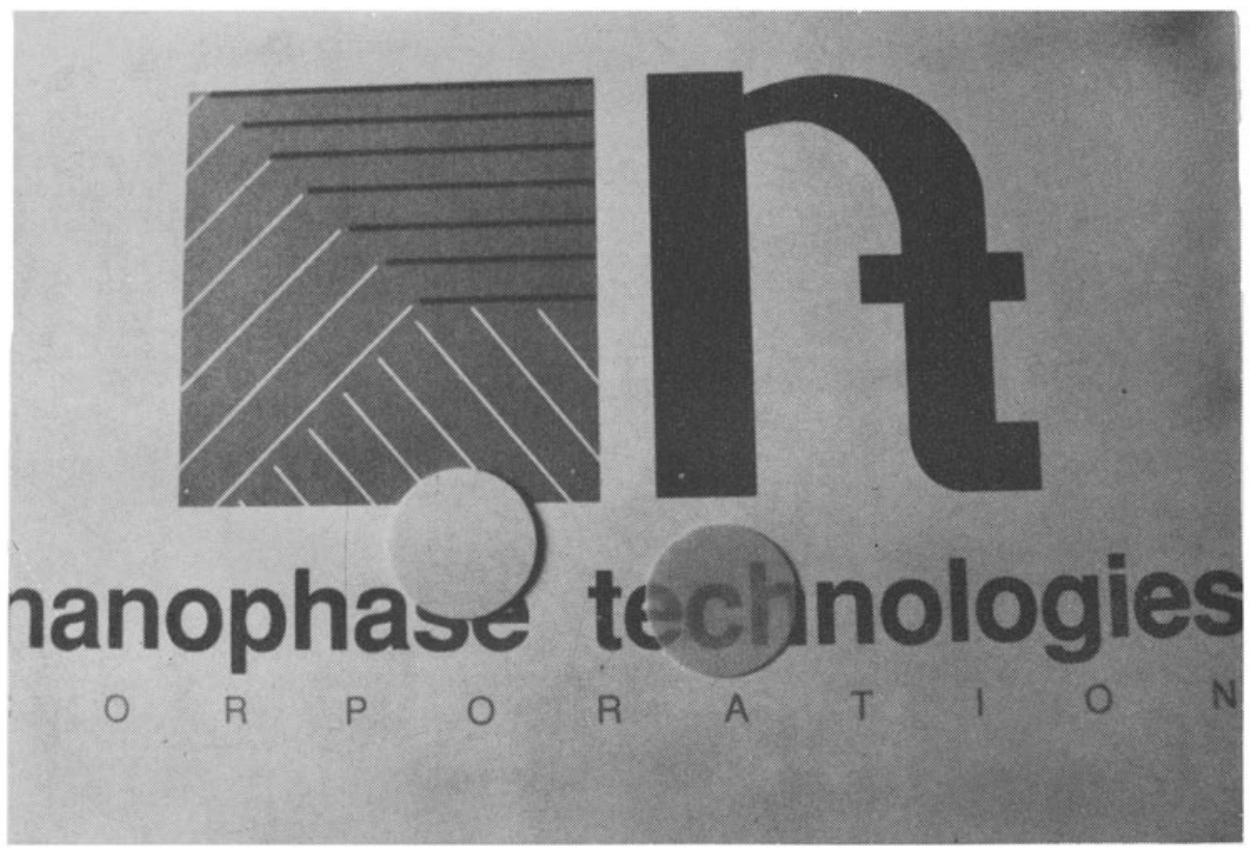

Figure 13. Disks of nanocrystalline $\mathrm{Y}_{2} \mathrm{O}_{3}$ showing that the optical transparency can be controlled by changing the pore size (Parker $\mathrm{J} \mathrm{C}$, private communication).

(which are much smaller than the wavelength of visible light) do not scatter light and so the samples are fairly transparent. On the other hand, the sample on the left has a higher degree of aggregation (i.e. larger pores), which causes enough scattering of light to make the sample opaque (Skandan et al 1991). Similarly, by controlling the cluster size in CdSe (by chemically capping them), Steigerwald and Brus (1989) were able to synthesize clusters of very narrow size distributions and show that they indicate varying degrees of quantum confinement and different bandgaps. For example, clusters of $1.2-1.5 \mathrm{~nm}$ diameter have a bandgap of $3.0 \mathrm{eV}$, those with a diameter of $3.0-3.5 \mathrm{~nm}$ have a bandgap of $2 \cdot 3 \mathrm{eV}$, while the bulk material has a bandgap of $1.8 \mathrm{eV}$.

Recently, it has been shown that visually transparent compacts could be produced by pressing $16 \mathrm{~nm}$-diameter silicon nitride $\left(\mathrm{Si}_{3} \mathrm{~N}_{4}\right)$ amorphous powder particles without outgassing and at liquid nitrogen temperature. This transparency continued to be exhibited even after subsequent pressureless sintering conducted for $1 \mathrm{~h}$ at $1400^{\circ} \mathrm{C}$ (Pechenik et al 1992). However, samples compacted at room temperature showed some degree of translucency suggesting that cooling the powder without outgassing to liquid nitrogen temperature prevents the particles from developing strong bonds prematurely.

\subsection{Magnetic properties}

The ferromagnetic properties of materials are influenced by changes in the interatomic distances. Thus, the saturation magnetization $\left(M_{s}\right)$ and ferromagnetic transition temperature of nanocrystalline materials are considerably reduced with respect to 
the bulk materials. The $M_{s}$ of $6 \mathrm{~nm}$-iron is $130 \mathrm{emu} / \mathrm{g}$ (Birringer et al 1986), while that of normal polycrystalline $\alpha-\mathrm{Fe}$ is $220 \mathrm{emu} / \mathrm{g}$, and that in iron-base metallic glasses (extrapolated to pure iron) is $215 \mathrm{emu} / \mathrm{g}$. Similarly, a reduction of the Curie temperature ( $T_{c}$ ) of $\mathrm{Ni}$ by about $40^{\circ} \mathrm{C}$ was reported if the crystal size was reduced to about $70 \mathrm{~nm}$ (Valiev et al 1989). These reductions were attributed to the deviation of interatomic spacings in the interfacial regions as compared to the crystalline component; supported by Mössbauer spectroscopy measurements (Ramasamy et al 1990). In the case of nanocrystalline erbium, at the lower end of the $10-70 \mathrm{~nm}$ grain size, the three normally observed magnetic transitions vanished and a low-temperature transition to superparamagnetic behaviour was detected. On the other hand, at larger grain sizes, these three magnetic transitions reappeared, but at different temperatures, while the low-temperature superparamagnetic behaviour was retained (Cowen et al 1987).

Recently, attractive magnetic properties have been reported for nanocrystalline Fe-base alloys obtained by crystallizing an amorphous alloy ribbon produced by the rapid solidification method (Yoshizawa et al 1988). This triggered a tremendous amount of activity in this area to optimize the soft magnetic properties of nanocrystalline alloys for potential applications. These materials are sometimes referred to as FINEMET since they have an ultrafine grain structure of $b c c \alpha-\mathrm{Fe}$ solid solution in an amorphous matrix.

Nanocrystalline alloys to obtain the best soft magnetic properties are produced by the addition of $\mathrm{Cu}$ and at least one element selected from the group consisting of $\mathrm{Nb}, \mathrm{W}, \mathrm{Ta}, \mathrm{Zr}, \mathrm{Hf}, \mathrm{Ti}$ and $\mathrm{Mo}$ to an iron-base alloy having an essential composition of $\mathrm{Fe}_{74.5-x} \mathrm{Cu}_{x} \mathrm{Nb}_{3} \mathrm{Si}_{13.5} \mathrm{~B}_{9}$ (Yoshizawa et al 1988). In the as-rapidly solidified condition, the alloy has an amorphous structure. After annealing these ribbons in the temperature range of 500 to $600^{\circ} \mathrm{C}$ for $1 \mathrm{~h}$, they crystallize to form crystallites with a grain size of 10 to $12 \mathrm{~nm}$ dispersed in an amorphous matrix. These crystals have a $b c c \alpha-\mathrm{Fe}$ structure in which $\mathrm{Si}, \mathrm{B}$, etc. are dissolved. The amorphous alloy exhibits a single crystallization peak in the absence of $\mathrm{Cu}$. Two peaks are seen when copper is present (copper also increases the nucleation rate). and the temperature difference between these two peaks increases with increasing $\mathrm{Cu}$ content up to about 1 at. $\%$. This peak separation helps in conducting the crystallization studies between the two peak temperatures to obtain the desired morphology and microstructure. Presence of niobium increases the thermal stability of the material so that growth of $\alpha$-Fe crystals is retarded.

The magnetic properties of nanocrystalline materials obtained by the above method depend on the grain size. For example, Herzer $(1990,1991)$ and Herzer and Warlimont (1992) produced grain sizes in the range of 10 to $300 \mathrm{~nm}$ by annealing the amorphous $\mathrm{Fe}-\mathrm{Cu}-\mathrm{Nb}-\mathrm{Si}-\mathrm{B}$ alloy between $500^{\circ} \mathrm{C}$ and $900^{\circ} \mathrm{C}$ and found that the coercivities, $H_{c}$ and initial permeabilities, $\mu_{i}$ varied over several orders of magnitude. It was noted that with increasing grain size $d$, the coercivity steeply increases following a $d^{6}$ power law up to $50 \mathrm{~nm}$, runs through a maximum of $H_{c} \sim 30 \mathrm{~A} / \mathrm{cm}$ and then decreases for grain sizes above $150 \mathrm{~nm}$ according to the well-known $1 / d$ law for polycrystalline magnets (figure 14). The initial permeability was found to vary in a similar manner, essentially being inversely proportional to coercivity. However, mechanical alloying seems to be unsuitable for the production of soft magnetic low coercivity alloys, because of the significant introduction of internal strain into the highly magnetostrictive material, which is inevitably due to the process (Kuhrt and Schultz 1992). 


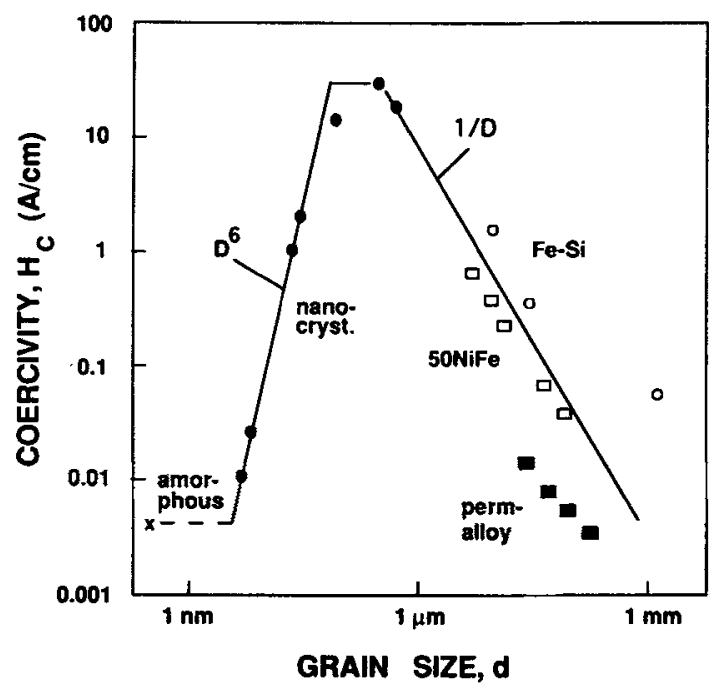

Figure 14. Grain size and coercivity for various soft magnetic materials (Herzer 1990).

Strain removal by annealing leads to undesirable grain growth. Thus, crystallization of amorphous alloy ribbons seems to be the only method available now-a-days to synthesize nanocrystalline alloys with attractive soft-magnetic properties.

The magnetic microstructure of nanocrystalline $\mathrm{Fe}$ was found to differ from that in polycrystalline or amorphous $\mathrm{Fe}$ and iron alloys. Whereas in both polycrystalline coarse-grained and amorphous alloys ferromagnetic domains are separated by domain walls, no domain structure was observed in nanocrystalline Fe by Bitter technique, Kerr microscopy, and Lorentz electron microscopy techniques (Gleiter 1992). In fact, every crystallite of a nanocrystalline Fe specimen appeared to be a single ferromagnetic domain.

The magnetic properties of nanocrystalline materials produced by crystallization of amorphous alloys show a good combination. They have a low coercivity ( 5 to $10 \mathrm{~A} / \mathrm{cm})$, high permeability $(100,000)$, almost zero magnetostriction $\left(0\right.$ to $\left.2 \times 10^{-6}\right)$, and low core losses $\left(\sim 200 \mathrm{~kW} / \mathrm{m}^{3}\right)$ due to the high electrical resistivity $(135 \mu \Omega \mathrm{cm})$. Further, the shape of the hysteresis loop can be tailored by magnetic field annealing. All the above characteristics, in combination with good thermal stability, suggest that nanocrystalline iron-based alloys are most promising candidates for soft-magnetic applications. Figure 15 compares the core losses of conventional coarse-grained $\mathrm{Fe}-3.5$ wt.\% $\%$ i, amorphous $\mathrm{Fe}-9$ at. $\% \mathrm{Si}-13$ at.\% $\mathrm{B}$, and nanocrystalline $\mathrm{Fe}-7$ at. $\% \mathrm{Zr}-1$ at.\% Cu-6 at. \%B alloys (Makino et al 1991). It can be clearly seen that the core losses are considerably low for the nanocrystalline material. Table 4 compares the magnetic properties of amorphous, coarse-grained, and nanocrystalline materials.

Another useful magnetic property that nanocomposites offer is called the magnetocaloric effect. When a material containing extremely small magnetic particulates in a non-magnetic or weakly magnetic matrix is placed in a magnetic field, the magnetic spins of the particulates tend to align with the field. This increase in magnetic order lowers the magnetic entropy of the spin system. If this process is performed adiabatically (i.e. no heat is exchanged with the surroundings), the reduction in spin entropy is offset by an increase in lattice entropy, and the specimen's temperature 

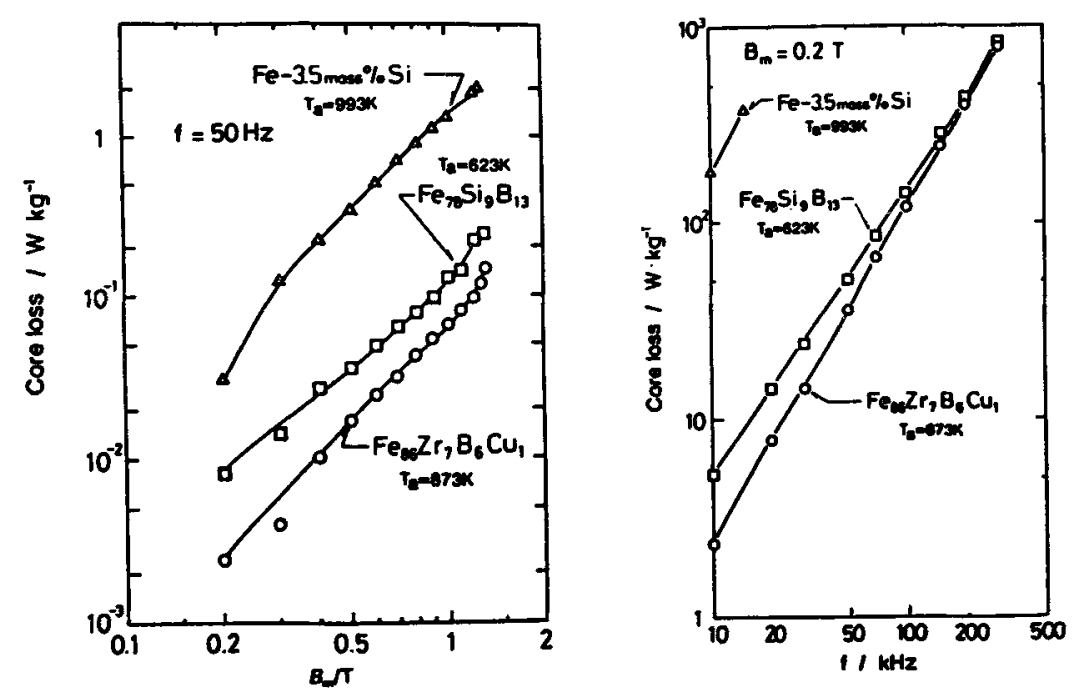

Figure 15. Comparison of core losses of conventional coarse-grained Fe-3.5 wt.\% $\%$, amorphous $\mathrm{Fe}-9$ at. $\% \mathrm{Si}-13$ at $\% \mathrm{~B}$, and nanocrystalline $\mathrm{Fe}-7$ at. $\% \mathrm{Zr}-1$ at. $\% \mathrm{Cu}-6$ at. $\% \mathrm{~B}$ alloys as a function of maximum induction field, $B_{m}$ and frequency, $f$ (Makino et al 1991).

will rise. This temperature rise, $\Delta T$, is reversible (the specimen cools down on removal of the magnetic field) and is known as the magnetocaloric effect. Shull and co-workers $(1992,1993 \mathrm{a}, \mathrm{b}$; McMichael et al 1992) have extensively investigated this phenomenon and predicted (Shull et al 1991) that the magnetocaloric effect may be enhanced at low fields and high temperatures. Shuil et al (1993a) have also shown that the magnetic nanocomposite $\mathrm{Gd}_{3} \mathrm{Ga}_{3.25} \mathrm{Fe}_{1.75} \mathrm{O}_{12}$ possesses magnetocaloric effect between $6 \mathrm{~K}$ and $30 \mathrm{~K}$ which at a magnetic field of 1 Tesla exceeds that of $\mathrm{Gd}_{3} \mathrm{Ga}_{5} \mathrm{O}_{12}$, the best paramagnetic refrigerant in this temperature range.

\subsection{Catalytic properties}

Since majority of the methods to produce bulk nanocrystalline materials involve consolidation of fine particles (except, for example, in crystallization of rapidly solidified amorphous alloy ribbons), the total surface area available can be accurately tailored by controlling the porosity in the samples. One can obtain full theoretical density to achieve the best mechanical properties or one can produce a highly porous material to obtain very large surface areas, or one can have an intermediate value of porosity.

Beck and Siegel (1992) have recently shown that the chemical reactivity of nanocrystalline $\mathrm{TiO}_{2}$ which has been only lightly consolidated (to maximize the porosity and hence the surface area) is significantly higher than that in other commercially available $\mathrm{TiO}_{2}$ samples. Figure 16 shows the catalytic activity for $\mathrm{S}$ removal from $\mathrm{H}_{2} \mathrm{~S}$ via decomposition for several forms of $\mathrm{TiO}_{2}$ having either the rutile or anatase structure with different surface areas. It can be seen that the nanocrystalline sample is far more reactive than any of the other samples, both initially and even after exposure for $7 \mathrm{~h}$; the activity for nanocrystalline $\mathrm{TiO}_{2}$ is about 5 times greater than 


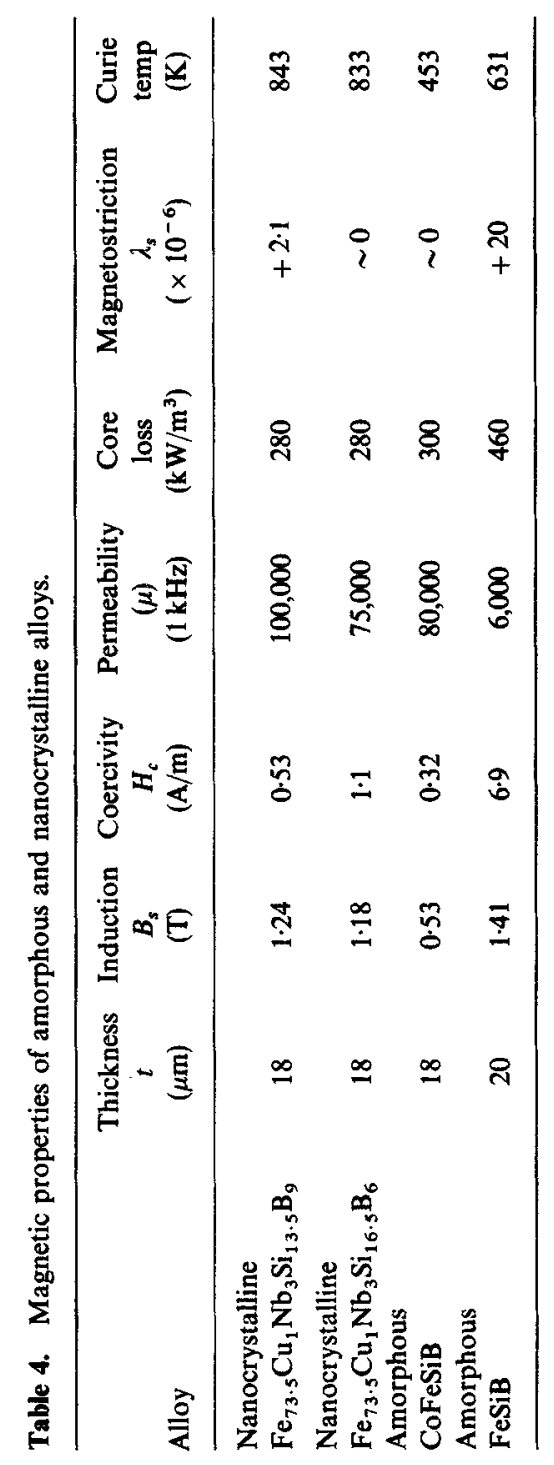




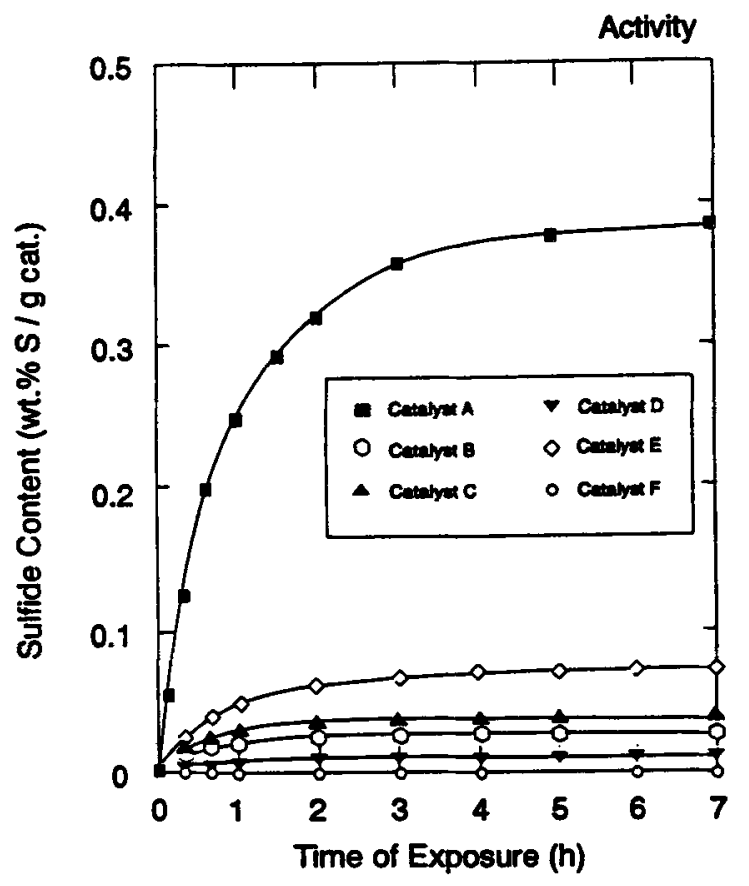

Figure 16. Activity of nanocrystalline $\mathrm{TiO}_{2}$ for $\mathrm{H}_{2} \mathrm{~S}$ decomposition as a function of exposure time at $500^{\circ} \mathrm{C}$ compared with that from several commercial $\mathrm{TiO}_{2}$ materials and a reference (A: $76 \mathrm{~m}^{2} / \mathrm{g}$ nanocrystalline rutile; B: $61 \mathrm{~m}^{2} / \mathrm{g}$ anatase; C: $2.4 \mathrm{~m}^{2} / \mathrm{g}$ rutile; D: $30 \mathrm{~m}^{2} / \mathrm{g}$ anatase; E: $20 \mathrm{~m}^{2} / \mathrm{g}$ rutile; and F: reference alumina) (Beck and Siegel 1992).

for the next most active materials. This greatly enhanced activity was shown to result from a combination of unique and controllable features of the nanocrystalline material-its high surface area combined with its rutile structure and its oxygen deficient composition. Annealing this material in an oxygen atmosphere decreased the number of anion vacancies and lowered the activity.

\subsection{Corrosion behaviour}

The corrosion behaviour of nanocrystalline materials has received very little attention until recently. Thorpe et al (1988) studied the corrosion behaviour of nanocrystalline $\mathrm{Fe}_{32} \mathrm{Ni}_{36} \mathrm{Cr}_{14} \mathrm{P}_{12} \mathrm{~B}_{16}$ alloy obtained by crystallization of the melt-spun amorphous ribbon, while Rofagha et al $(1991,1993)$ studied nanocrystalline $\mathrm{Ni}-\mathrm{P}$ produced by the electrodeposition technique.

The average dissolution rate of nanocrystalline $\mathrm{Ni}$ was found to be higher than that for coarse-grained material. However, while coarse-grained Ni suffers excessive intergranular corrosion in acidic media, nanocrystalline $\mathrm{Ni}$ exhibited more uniform corrosion morphology (Rofagha et al 1991). Superior localized corrosion resistance in $\mathrm{HCl}$ was observed for sputter deposited nanocrystalline 304 stainless steel in comparison with conventional material; attributed to the fine grain size and homogeneity of the nanocrystalline material (Inturi and Szklarska-Smialowska 1992). A similar behaviour was noted in the $\mathrm{Fe}-\mathrm{Ni}-\mathrm{Cr}-\mathrm{P}-\mathrm{B}$ alloy and the improvement was explained 
in terms of $\mathrm{Cr}$ enrichment of the specimen surface as a result of having more rapid grain boundary diffusion paths (Thorpe et al 1988).

Nanocrystalline $\mathrm{Ni}-\mathrm{P}$ alloys were non-passivating in $0 \cdot 1 \mathrm{M} \mathrm{H}_{2} \mathrm{SO}_{4}$. Their enhanced dissolution rates over those of conventional polycrystalline nickel was explained as due to the presence of $\boldsymbol{P}$ and the high volume fraction of grain boundaries and triple junctions. Further, anodic polarization of the nanocrystalline material resulted in the formation of non-protective surface films.

\section{Applications}

Nanocrystalline materials are relatively new and it is only during the past five years that researchers have started exploring the many potential benefits of these materials. Although no component made of a nanocrystalline material is in use in any industry now, several potential applications are suggested, based on their special attributes.

It has been known that the fracture toughness of ceramics can be considerably enhanced by dispersing a second phase on a microscopic scale. Since reducing the grain size to nanometer-dimensions can provide increased strength and hardness, it is suggested that fabrication of micro/nanohybrids will lead to a class of supertough and superstrong ceramics. In these hybrids, a nanocomposite matrix is reinforced with micron-sized particles-whiskers, platelets, and long fibers--and these hybrids show enhanced fracture toughness and strength up to very high temperatures, where the properties of coarse-grained composites normally degrade. Such superceramics may find use in severe engineering applications such as high efficiency gas turbines, and in aerospace and automotive components.

Nanocrystalline WC-Co composites produced by Nanodyne, Inc. have been shown to have higher hardness or toughness, four times better wear resistance (figure 17),

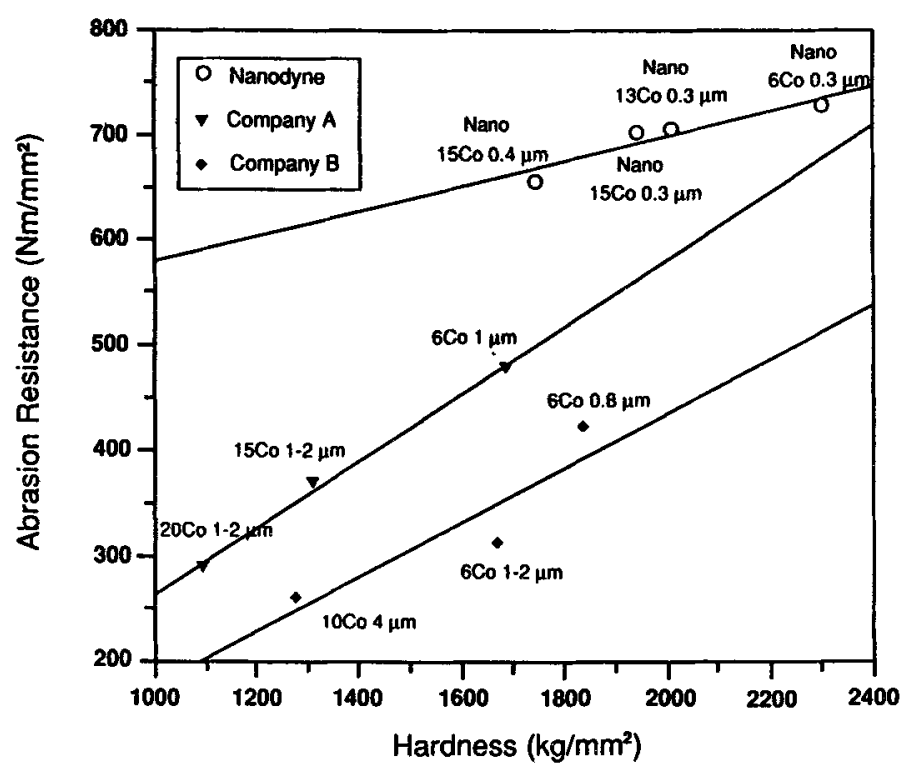

Figure 17. Abrasion resistance vs hardness of conventional and nanocrystalline WC-Co materials (L E McCandlish 1994). 
and more than double lifetime in cutting tools than conventional coarse-grained composites. Thus, the nanocrystalline powders can be made into wear-resistant coatings or pressed and sintered to make rigid objects. Applications for such powders include fine drill bits for drilling holes in printed circuit boards and rotary cutting tools (due to the fine grain size, sharp edges, and smooth surface finish), turbine blade coatings, and other high-wear applications.

Since the optical transparency of nanocrystalline ceramics can be controlled by controlling the grain size and porosity in them, they may find application in sensor and filtration technology.

The increased diffusion rates in nanocrystalline metals and ceramics considerably reduce the temperatures at which sintering can occur in these materials. The enhanced diffusivity can be used to make oxygen sensors and fuel cells capable of operating at much lower temperatures than systems currently in use today. Nanocrystalline ceramics may also be a good candidate material for joining ceramic parts. The usual problems in joining conventional ceramics - requirements of high pressures and temperatures for diffusion bonding and non-retention of strength at elevated temperatures for reactive braze metals and molten glass - can be overcome with nanocrystalline ceramics due to their high diffusivity and superplastic forming characteristics.

The electrical and magnetic properties of nanocrystalline materials will probably form the basis of their wide-spread and industrial applications. The phenomenon of giant magnetoresistance (GMR) is now shown to be present even in equiaxed nanocrystalline materials. The resistance drop is as much as 50 to $80 \%$ (at liquid helium temperature) whereas it is only 1 or $2 \%$ in a nickel-iron (permalloy) magnetoresistive sensor in a weak magnetic field. Thus, materials exhibiting this large GMR can be promising candidates for the reading heads of the next generation of information storage systems. However, it should be noted that the large GMR can be observed only when the applied magnetic field is about 10,000 Gauss (1 Tesla) whereas in a permalloy it can be observed at a field of only 10 Gauss.

The excellent combination of soft magnetic properties can be useful in producing tape-wound cores for common mode chokes, saturable reactors, high frequency transformers, and magnetic heads. Another useful property of nanocomposites is the magnetocaloric effect. Upon cycling (placing and removing of the magnetic field), the magnetocaloric effect can be used for transferring heat from one thermal reservoir to another. Thus, the magnetocaloric effect can be used for magnetic refrigeration (solid magnetic materials rather than compressed gases-and also avoiding the harmful CFC's). Materials being used for this purpose include $\mathrm{Gd}_{3} \mathrm{Ga}_{3 \cdot 25} \mathrm{Fe}_{1 \cdot 75} \mathrm{O}_{12}$, $\gamma-\mathrm{Fe}_{2} \mathrm{O}_{3}$ stabilized in an ion-exchange resin, etc.; and these can be used at temperatures of 65 or $70 \mathrm{~K}$ in comparison with $<15 \mathrm{~K}$ for the present-day magnetic refrigerator substance $\mathrm{Gd}_{3} \mathrm{Ga}_{5} \mathrm{O}_{12}$.

\section{Concluding remarks}

Nanocrystalline materials are novel materials which are not only scientifically interesting but also hold great potential for varied applications. Their properties are different from and often superior to those of conventional coarse-grained polycrystalline materials and also amorphous alloys of the same composition. 
It has been shown that by decreasing the grain size to nanometer levels, traditionally soft and ductile metals can be made very hard and strong (and brittle?) and conventional ceramics which are brittle can be made to plastically deform like metals. The enhanced diffusivity in these materials results in increased solid solubilities, and synthesis of alloy phases from normally difficult-to-alloy metals and also allows to sinter powder compacts at temperatures much lower than those required for coarse-grained polycrystalline materials. The electrical, optical, chemical, and magnetic properties have also been found to be superior in the nanocrystalline state in comparison with the coarse-grained material.

Most of the early results were based on materials produced by the gas-condensation technique, and porosity (very often an undetermined quantity in the early studies) was an integral part of the material. The properties of these materials were interpreted on the basis of a two-component mixture-crystalline and interfacial componentswhereas they should have been interpreted by taking into account the porosity as well. In fact, reduction in Young's modulus values (Krstic et al 1993), increased diffusivities and, in general, variations in mechanical and physical properties have now been ascribed to the presence of porosity in these materials.

Widespread use and search for technological applications of nanocrystalline materials requires the availability of large (tonnage) quantities of well-characterized material with reproducible properties; and this needs to be done economically. A solution to these barriers can be identification of well-defined applications for these nanocrystalline materials and this can be a driver for accelerated research. In this context, development of novel techniques is an urgent necessity. Developments in this field thus parallel those of rapidly solidified (RS) metals (Anantharaman and Suryanarayana 1987; Liebermann 1993). Even though the RS materials exhibited a very interesting combination of properties, industrial exploitation of these materials had to await innovations of new techniques - the melt spinning and planar flow casting methods. A similar revolution can be expected in the field of nanocrystalline materials, especially with the launching of new companies to produce the powders commercially.

Consolidation of the fine powders and the thermal stability of the nanometer-sized grains is another concern of materials scientists. It is gratifying to note that optimization of process parameters to consolidate these materials to full density is being recently reported. Although the mechanisms are not clear, the grain growth appears to be minimum and this augurs well for the future of nanocrystalline materials.

The majority of investigations on nanocrystalline materials to date have been concerned with materials having a grain size of 10-100 nm. Conventional fine-grained polycrystalline materials have grain sizes of about $10,000 \mathrm{~nm}(10 \mu \mathrm{m})$ or larger. Hence, materials with grain sizes of about 100 to $1000 \mathrm{~nm}$ and also those in the $1-$ to $2-\mathrm{nm}$ range should be evaluated to determine the full range of possible properties as a function of grain size.

The optical, electrical, and magnetic properties of nanocrystalline materials can now be 'tailored' by contrqling the grain size and porosity heralding in the principles of alloy design into this new class of materials. For this line of investigations to grow rapidly, it is mandatory that improved characterization techniques become available so that the crystalline and interfacial components can be fully characterized. Additionally, characterization of the material with respect to porosity is important since this has been shown to affect the diffusivity, grain growth and mechanical properties. Work on modelling of these materials also has just begun (Bush 1993). 
Two exciting possibilities using the nanocrystalline materials are being explored now. One of these is nanoglasses wherein nanometer-sized glassy particles are produced and these are consolidated to a bulk shape (Jing et al 1989). Since glassy materials have been shown to have properties vastly improved over their crystalline counterparts, nanoglasses can be expected to exhibit properties superior to those of even nanocrystalline materials. Another possibility is the synthesis of nanocomposites-even more important in ceramics. Here, one can disperse nanometer-sized particles inside the grains, along the grain boundaries, or both, of coarse-grained or nanocrystalline ceramics and such materials are shown to have an excellent combination of strength and ductility.

This review was concerned essentially with the synthesis, structure, and properties of three-dimensional nanocrystalline materials. Exciting developments are also occurring in one-dimensional layered nanostructures, e.g. supermodulus effect, enhanced wear behaviour, etc.

It is only during the last year or two that clear comparisons are being made amongst nanocrystalline, conventional coarse-grained polycrystalline, and amorphous alloys (of the same chemical composition) as potential engineering materials. This should slowly clear the way to unambiguously establish the characteristics of nanocrystalline materials as superior to the other two categories. Based on what we know so far, the future for nanocrystalline materials seem to have been well established.

Sir Alan Cottrell (1992) recently pointed out that 'all materials consist of electrons and nuclei...However, nature has the ability to magnify small variations into vast differences', and nanocrystalline materials are a perfect example of how the properties can be vastly modified by decreasing the grain size. It also appears that we are now on the verge of making true Feynman's (1991) statement that 'I can hardly doubt that when we have some control of the arrangement of things on a small scale we will get an enormously greater range of possible properties that substances can have.'

\section{Acknowledgements}

The author has greatly benefitted from many discussions with several researchers in the field. I would like to especially thank Prof. H Gleiter, Universitat des Saarlandes, Saarbrucken, Germany; Dr R W Siegel, Argonne National Laboratory, Argonne, IL, USA; Dr R D Shull, National Institute of Standards \& Technology, Gaithersburg, MD, USA; Prof. Carl C Koch, North Carolina State University, Raleigh, NC, USA; Prof. K Lu, Institute of Metal Research, Academia Sinica, Shenyang, P.R. China and Prof. F H Froes, University of Idaho, Moscow, ID, USA.

\section{References}

Anantharaman T R and Suryanarayana C 1987 Rapidly solidified metals: A technological overview (Aedermannsdorf, Switzerland: Trans Tech Publ.)

Andres R P et al 1989 J. Mater. Res. 4704

Andrievski R A 1994 J. Mater. Sci. 29614

Armstrong R W 1983 in Yield, flow and fracture of polycrystals (ed) T N Baker (London: Appl. Sci. Pub) p. 1

Averback R S, Hahn H, Höfler H J, Logas J L and Chen T C 1989 Mater. Res. Soc. Symp. Proc. 1583

Averback R S, Höfler H J and Tao R 1993 Mater. Sci. Engg. A166 169

Baibich N B et al 1988 Phys. Rev. Lett. 612472 
Bakonyi I, Toth-Kadar E, Tarnoczi T, Varga L, Cziraki A, Gerocs I and Fogarassy B 1993 Nanostr. Mater. 3155

Beck D D and Siegel R W 1992 J. Mater. Res. 72840

Benjamin J S 1976 Sci. Am. 23440

Berkowitz A E and Walter J L 1987 J. Mater. Res. 2277

Berkowitz A E et al 1992 Phys. Rev. Lett. 683745

Bickerdike R L, Clark D, Easterbrook J N, Hughes G, Mair W N, Partridge P G and Ranson H C 1984-85 Int. J. Rapid Solidification 1305

Birringer R 1989 Mater. Sci. Engg. A117 33

Birringer R, Gleiter H, Klein H P and Marquart P 1984 Phys. Lett. A102 365

Birringer R, Herr U and Gleiter H 1986 Suppl. Trans. Jpn. Inst. Metals 2743

Birringer R, Hahn H, Höfler H J, Karch J and Gleiter H 1988 Defect \& Diff. Forum 5917

Boylan K, Ostrander D, Erb U, Palumbo G and Aust K T 1991 Scr. Metall. Mater. 252711

Bush M B 1993 Mater. Sci. Engg. A161 127

Chang H, Altstetter C J and Averback R S 1992 J. Mater. Res. 72962

Chen L C and Spaepen F 1988 Nature (London) 336366

Cho Y S and Koch C C 1991 Mater. Sci. Engg. A141 139

Chokshi A H, Rosen A, Karch J and Gleiter H 1989 Scr. Metall. 231679

Chou C-H and Phillips J 1992 J. Mater. Rés. 72107

Christman T 1993 Scr. Metall. Mater. 281495

Coble R L 1963 J. Appl. Phys. 341679

Cottrell A H 1992 Metals \& Mater. 810

Cowen J A, Stolzmann B, Averback R S and Hahn H 1987 J. Appl. Phys. 613317

Dagani R 1992 Chem. \& Engg. News 7018

El-Kaddah N (ed) 1992 Thermal plasma applications in materials and metallurgical processing (Warrendale, PA: TMS)

El-Sherik A M, Erb U, Palumbo G and Aust K T 1992 Scr. Metall. Mater. 271185

Feynman R 1991 Science 2541300

Fougere G E, Weertman J R, Siegel R W and Kim S 1992 Scr. Metall. Mater. 261879

Fougere G E, Weertman J R and Siegel R W 1993 Nanostr. Mater. 3379

Froes F H and Suryanarayana C 1989 JOM 4112

Ganapathi S K and Rigney D A 1990 Scr. Metall. Mater. 241675

Ganapathi S K, Owen D M and Chokshi A H 1991 Scr. Metall. Mater. 252699

Gertsman V Y and Birringer R 1994 Scr. Metall. Mater. 30577

Gleiter H 1981 in Deformation of polycrystals: Mechanisms and microstructures, (eds) N Hansen, A Horsewell, T Leffers and H Lilholt (Roskilde, Denmark: Riso National Laboratory) pp. 15-21

Gleiter H 1989 Prog. Mater. Sci. 33223

Gleiter H 1992 Nanostr. Mater. 11

Groza J R 1994 Scr. Metall. Mater. 3047

Gryaznov V G, Solov'ev V A and Trusov L I 1990 Scr. Metall. Mater. 241529

Gryaznov V G, Tanakov M Yu and Trusov L I 1992 J. Mater. Sci. 274829

Gryaznov V G, Gutkin M Yu, Romanov A E and Trusov L I 1993 J. Mater. Sci. 284359

Guermazi M, Höfler H J, Hahn H and Averback R S 1991 J. Am. Ceram. Soc. 742672

Haas V, Gleiter H and Birringer R 1993 Scr. Metall. Mater. 28721

Hahn H, Höfler H J and Averback R S 1989 Defect \& Diff. Forum 66-69 549

Hahn H, Logas J and Averback R S 1990 J. Mater. Res. 5609

Hall E O 1951 Proc. Phys. Soc. (London) B64 747

Hellstern E, Fecht H, Fu Z and Johnson W L 1989 J. Appl. Phys. 65305

Herzer G 1990 IEEE Trans. MAG26 1397

Herzer G 1991 Mater. Sci. Engg. A133 1

Herzer G and Warlimont H 1992 Nanostr. Mater. 1263

Höfler H J and Averback R S 1990 Scr. Metall. Mater. 242401

Horvath J 1989 Defect \& Diff. Forum 66-69 207

Horvath J, Birringer R and Gleiter H 1987 Solid State Commun. 62319

Hughes G D, Smith S D, Pande C S, Johnson H R and Armstrong R W 1986 Scr. Metall. 2093

Inturi R B and Szklavska-Smialowska Z 1992 Corrosion 48398

Isonishi K and Okazaki K 1993 J. Mater. Sci. 283829 
Ivanov E 1992 Mater. Sci. Forum 88-90 475

Jang J S C and Koch C C 1988 Scr. Metall: 22677

Jang J S C and Koch C C 1990 Scr. Metall. Mater. 241599

Jing J, Krämer A, Birringer R, Gleiter H and Gonser U 1989 J. Non-Cryst. Solids 113167

Joyce Jr E L and Jervis T R 1988 Scr. Metall. 221313

Karch J and Birringer R 1990 Ceram. Int. 16291

Karch J, Birringer R and Gleiter H 1987 Nature (London) 330556

Kawanishi S, Isonishi K and Okazaki K 1993 Mater. Trans. JIM 3449

Kear B H and McCandlish L E 1993 Nanostr. Mater. 319

Kim D K and Okazaki K 1992 Mater. Sci. Forum 88-90 553

Klam H J, Hahn H and Gleiter H 1987 Acta Metall. 352101

Knauth P, Charai A and Gas P 1993 Scr. Metall. Mater. 28325

Koch C C 1991 in Processing of metals and alloys, vol. 15 of Materials Science and Technology (ed) R W Cahn (Weinheim, Germany: VCH) pp. 193-245

Koch C C 1993 Nanostr. Mater. 2109

Korth G E 1993 in Advanced synthesis of engineered structural materials (eds) J J Moore, E J Lavernia and F H Froes (Materials Park, OH: ASM International) pp. 81-86

Köster U, Schünemann U, Blak-Bewersdorff M, Brauer S, Sutton M and Stephenson G B 1991 Mater. Sci. Engg. A133 611

Köster U, Alves H and Meinhardt J 1994 in Proc. of inter. conf. on advanced materials (ICAM-93), (eds) S Somiya, M Doyama, M Hasegawa and S Yamada (Amsterdam: Elsevier Sci. Pub.) (in press)

Kriechbaum G W and Kleinschmitt P 1989 Adv. Mater. 1330

Krstic V; Erb U and Palumbo G 1993 Scr. Metall. Mater. 291501

Kuhrt Ch and Schultz L 1992 J. Appl. Phys. 711896

Kumpmann A, Günther B and Kunze H-D 1993 Mater. Sci. Engg. A168 165

Lashmore D S and Dariel M P 1988 in Encyclopedia of materials science and engineering, (ed) R W Cahn (Oxford, UK: Pergamon) suppl. vol. 1, pp. 136-140

Le Brun P, Gaffet E, Froyen L and Delaey L 1992 Scr. Metall. Mater. 261743

Li D X, Ping D H, Ye H Q, Qin X Y and Wu X J 1993 Mater. Lett. 1829

Li S, Sun L and Wang Z 1993 Nanostr. Mater. 2653

Li Z, Hahn H and Siegel R W 1988a Mater. Lett. 6342

Li Z, Ramaswamy S, Hahn H and Siegel R W 1988b Mater. Lett. 6195

Lian J and Baudelet B 1993 Nanostr. Mater. 2415

Liebermann H H (ed) 1993 Rapidly solidified alloys: Processes, structures, properties and applications (New York: Marcel Dekker, Inc.)

Liu X D, Hu Z Q and Ding B Z 1993a Nanostr. Mater. 2545

Liu X D, Wang J T and Ding B Z 1993b Scr. Metall. Mater. 2859

Liu X D, Wang J T and Zhu J 1994 J. Mater. Sci. 29929

Lu K 1991 Scr. Metall. Mater. 252047

Lu K 1993 Nanostr. Mater. 2643

Lu K and Sui M L 1993 Scr. Metall. Mater. 281465

Lu K, Wei W D and Wang J T 1990 Scr. Metall. Mater. 242319

Lu K, Wang Y Z, Wei W D and Li Y Y 1991a Adv. Cryo. Mater. 38285

Lu K, Wei W D and Wang J T 1991b J. Appl. Phys. 697345

Lu K, Wang J T and Wei W D 1991c Scr. Metall. Mater. 25619

Lu K, Wang J T and Wei W D 1992 J. Phys. D. Appl. Phys. 25808

Makino A, Suzuki K, Inoue A and Masumoto T 1991 Mater. Trans. JIM 32551

Mandich M L, Bondybey V E and Reents W D 1987 J. Chem. Phys. 864245

Masumoto T 1994 Mater. Sci. Engg. A179

Mayo M J 1993 Mater. \& Design 14323

Mayo M J, Siegel R W, Narayanasamy A and Nix W D 1990 J. Mater. Res. 51073

Mayo M J, Siegel R W, Liao Y X and Nix W D 1992 J. Mater. Res. 7973

McCandlish L E 1994 Private Communication

McMahon G and Erb U 1989 Microstr. Sci. 17447

McMichael R D, Shull R D, Swartzendruber L J, Bennett L H and Watson R E 1992 J. Magn. Mater. 11129

Melendres C A, Narayanasamy A, Maroni V A and Siegel R W 1989 J. Mater. Res. 41246 
Mütschele T and Kirchheim R 1987a Scr. Metall. 21135

Mütschele T and Kirchheim R 1987b Scr. Metall. 211101

Nieh T G and Wadsworth J 1991 Scr. Metall. Mater. 25955

Nieman G W and Weertman J R 1991 in Proc. M. E. Fine symposium (eds) P K Liaw et al (Warrendale, PA: TMS) pp. 243-250

Nieman G W, Weertman J R and Siegel R W 1990 Scr. Metall. Mater. 24145

Nieman G W, Weertman J R and Siegel R W 1991a in Clusters and cluster-assembled materials (eds) R S Averback, J Bernholc and D L Nelson (Pittsburgh, PA: MRS) 206493

Nieman G W, Weertman J R and Siegel R W 1991b J. Mater. Res. 61012

Okazaki K 1993 in Advanced synthesis of engineered structural materials, (eds) J J Moore, E J Lavernia and F H Froes (Materials Park, OH: ASM International) pp. 197-204

Ouyang H, Fultz B and Kuwano H 1993 in Nanophases and nanocrystalline structures, (eds) R D Shull and J M Sanchez (Warrendale, PA: TMS) pp. 95-104

Palatnik L S, Il'inskii A I and Sapelkin N P 1967 Soviet Phys.-Solid State 82016

Palumbo G, Erb U and Aust K T 1990a Scr. Metall. Mater. 242347

Palumbo G, Thorpe S J and Aust K T 1990b Scr. Metall. Mater. 241347

Pande C S, Masumura R A and Armstrong R W 1993 Nanostr. Mater. 2323

Parker J C and Siegel R W 1990a J. Mater. Res. 51246

Parker J C and Siegel R W 1990b Appl. Phys. Lett. 57943

Pechenik A, Piermarini G J and Danforth S C 1992 J. Am. Ceram. Soc. 753283

Petch N J 1953 J. Iron \& Steel Inst. 17425

Rabukhin V B 1986 Phys. Met. Metall. 61149

Ramasamy S, Jiang J, Gleiter H, Birringer R and Gonser U 1990 Solid State Commun. 74851

Ranganathan S and Suryanarayana C 1985 Mater. Sci. Forum 3173

Reiss G, Vancea J and Hoffmann H 1986 Phys. Rev. Lett. 562100

Rigney D A 1988 Ann. Rev. Mater. Sci. 18141

Ritter J J, Minor D B, McMichael R D and Shull R D 1993 in Nanophases and nanocrystalline structures, (eds) R D Shull and J M Sanchez (Warrendale, PA: TMS) pp. 33-40

Rofagha R, Erb U, Ostrander D, Palumbo G and Aust K T 1993 Nanostr. Mater. 21

Rofagha R, Langer R, El-Sherik A M, Erb U, Palumbo G and Aust K T 1991 Scr. Metall. Mater. 252867

Roy R A and Roy R 1984 Mater. Res. Bull. 19169

Rupp J and Birringer R 1987 Phys. Rev. B36 7888

Scattergood R O and Koch C C 1992 Scr. Metall. Mater. 271195

Schaefer H E, Würschum R, Birringer R and Gleiter H 1988 J. Less-Common Metals 140161

Schumacher S, Birringer R, Strauss R and Gleiter H 1989 Acta Metall. 372485

Shingu P H, Huang B, Nishitani S R and Nasu S 1988 Suppl. Trans. Jpn. Inst. Metals 293

Shull R D 1993 Nanostr. Mater. 2213

Shull R D, Swartzendruber L J and Bennett L H 1991 in Proc. 6th inter. cryocoolers conference (eds) G Green and M Knox (Annapolis, MD: David Taylor Research Center Pbl. \#DTRC-91/002) pp. 231-245

Shull R D, McMichael R D, Swartzendruber L J and Bennett L H 1992 in Studies of magnetic properties of fine particles and their relevance to materials science (eds) J L Dormann and D Fiorani (Amsterdam: Elsevier Sci. Publ.) pp 161-169

Shull R D, McMichael R D and Ritter J J 1993a Nanostr. Mater. 2205

Shull R D, McMichael R D, Ritter J J and Bennett L H 1993b Mater. Res. Soc. Symp. Proc. 286449

Siegel R W 1990 MRS Bulletin 1560

Siegel R W 1991a Ann. Rev. Mater. Sci. 21559

Siegel R W 1991b in Processing of metals and alloys, vol. 15 of Materials Science and Technology (ed) R W Cahn (Weinheim, Germany: VCH) pp. 583-614

Siegel R W 1992 in Materials interfaces: atomic level structure and properties (eds) D Wolf and S Yip (London: Chapman \& Hall) p. 431

Siegel R W 1994 Nanostr. Mater. 4121

Siegel R W and Hahn H 1987 in Current trends in the physics of materials (ed) M Youssouff (Singapore: World Sci. Publ. Co.) pp. 403-419

Siegel R W and Thomas G J 1992 Ultramicroscopy 40376

Siegel R W, Ramasamy S, Hahn H, Li Z, Lu T and Gronsky R 1988 J. Mater. Res. 31367

Skandan G, Hahn H and Parker J C 1991 Scr. Metall. Mater. 252389 
Spassov T and Köster U 1993 J. Mater. Sci. 282789

Steigerwald M L and Brus L E 1989 Ann. Rev. Mater. Sci. 19471

Suryanarayana C 1984 in Metallic glasses (ed) T R Anantharaman (Aedermannsdorf: Trans Tech) pp 249-267

Suryanarayana C, Chen G H, Frefer A and Froes F H 1994 (Unpublished results)

Suryanarayana C and Froes F H 1989 in Physical chemistry of powder metals production and processing (ed) W M Small (Warrendale, PA: TMS) pp. 279-296

Suryanarayana C and Froes F H 1990 J. Mater. Res. 51880

Suryanarayana C and Froes F H 1992a Met. Trans. A23 1071

Suryanarayana C and Froes F H 1992b Nanostr. Mater. 1196

Suryanarayana C and Froes F H 1993 Nanostr. Mater. 3147

Suryanarayana C, Inoue A and Masumoto T $1980 \mathrm{~J}$. Mater. Sci. 141993

Suryanarayana C, Mukhopadhyay D, Patankar S N and Froes F H 1992 J. Mater. Res. 72114

Suryanarayana C, Korth G E, Chen G H, Frefer A and Froes F H 1993 Nanostr. Mater. 2527

Taylor P, Pirzada S A, Marshall D L and Donahue S M 1993 in Plasma synthesis and processing of materials, (ed) K Upadhya (Warrendale, PA: TMS) pp. 215-225

Thomas G J. Siegel R W and Eastman J A 1990 Scr. Metall. Mater. 24201

Thorpe S J, Ramaswami B and Aust K T 1988 J. Electrochem. Soc. 1352162

Tong H Y, Wang J T, Ding B Z, Jiang H G and Lu K 1992 J. Non-Cryst. Solids 150444

Trudeau M L, Van Neste A and Schultz R 1991 Mater. Res. Soc. Symp. Proc. 206487

Turnbull D 1981 Met. Trans. A12 695

Valiev R Z, Mulyukov R R, Mulyukov Kh Ya, Novikov V I and Trusov L I 1989 Pisma v Szurnal Teckhnicheskoi Fiz 1578

Wang K Y. Shen T D, Quan M X and Wei W K 1993 J. Mater. Sci. Lett. 121818

Wang Y Z, Qiao G W, Liu X D, Ding B Z and Hu Z Q 1993 Mater. Lett. 17152

Wunderlich W, Ishida Y and Maurer R 1990 Scr. Metall. Mater. 24403

Xiao J Q, Jiang J S and Chien C L 1992 Phys. Rev. Lett. 683749

Yoshizawa Y, Oguma S and Yamauchi K J 1988 J. Appl. Phys. 646044 